\title{
Do perceived control and time orientation mediate the effect of early life adversity on reproductive behaviour and health status? Insights from the European Value Study and the European Social Survey.
}

Bence Csaba Farkas ${ }^{1}$, Valérian Chambon ${ }^{2}$, Pierre O. Jacquet ${ }^{1}$

${ }^{1} \mathrm{LNC}^{2}$, Département d'études cognitives, École normale supérieure, INSERM, PSL Research University, 75005 Paris, France.

${ }^{2}$ Institut Jean Nicod, Département d'études cognitives, ENS, EHESS, CNRS, PSL Research University, 75005 Paris, France.

\section{Acknowledgements}

This work was supported by the FrontCog funding under grant number ANR-17-EURE-0017. POJ was supported by ANR-10-LABX-0087 IEC and ANR-10-IDEX-0001-02 PSL*. V.C. was supported by the Agence Nationale de la Recherch grants ANR-16-CE37-0012-01 (ANR JCJ) and ANR-19-CE37-0014-01 (ANR PRC).

\section{Competing interests}

The authors declare no competing interests.

\section{Corresponding Authors}

Bence Csaba Farkas

E-Mail address: bence.farkas@ens.psl.eu

ORCID : http://orcid.org/0000-0003-1815-5054

Pierre O. Jacquet

E-Mail address: pierre.ol.jacquet@gmail.com

ORCID : https://orcid.org/0000-0002-6495-5581

Département d'Etudes Cognitives, Ecole Normale Supérieure, PSL Research University, 29, rue d’Ulm, F-75005 Paris, France. Voice: +33144322640

\section{Word count}

7972 (including figures and tables legends; excluding abstract and references) 


\begin{abstract}
An association between early life adversity and a range of coordinated behavioural responses that favour reproduction at the cost of a degraded health is often reported in humans. Recent theoretical works have proposed that perceived control - i.e., people's belief that they are in control of external events that affect their lives - and time orientation - i.e., their tendency to live on a day-to-day basis or to plan for the future - are two closely related psychological traits mediating the associations between early life adversity, reproductive behaviours and health status. However, the empirical validity of this hypothesis remains to be demonstrated. In the present study, we examine the role of perceived control and time orientation in mediating the effects of early life adversity on a trade-off between reproductive traits (age at $1^{\text {st }}$ childbirth, number of children) and health status by applying a cross-validated structural equation model frame on two large public survey datasets, the European Values Study (EVS, final $N=43084$ ) and the European Social Survey (ESS, final $N=31$ 065). Our results show that early life adversity, perceived control and time orientation are all associated with a trade-off favouring reproduction over health. However, perceived control and time orientation mediate only a small portion of the effect of early life adversity on the reproduction-health trade-off.
\end{abstract}

\title{
Keywords
}

Early life adversity; Perceived control; Time orientation; Life History theory; Structural equation modelling; Cross-validation 


\section{Introduction}

Socioeconomic inequality is on the rise. In the US, in 2016, the wealthiest $1 \%$ owned about $40 \%$ of the country's total wealth (Zucman, 2019). This is a massive increase compared to the 1980's, when this value never exceeded 30\%. Similar trends can be observed in Europe and China (Piketty \& Saez, 2014; Zucman, 2019). Such drastic worldwide inequality leaves many people struggling with poverty and its consequences for many aspects of human life.

In fact, economic scarcity often comes together with other environmental factors that cumulatively contribute to reduced well-being and shorter lifespan (Pepper \& Nettle, 2017). For that reason, these factors are collectively termed 'adversity'. Economic scarcity, violence and maltreatment, physical and affective instabilities within the family household, exposure to pollutants, or malnutrition, are all considered factors of adversity. When met early in life - that is, from conception to adolescence - these factors interfere with the developmental trajectories of many human biological systems, including growth and energy storage (Kuzawa et al., 2014), immunity (McDade, 2005; McDade et al., 2016), reproduction (Bar-Sadeh et al., 2020; Mell et al., 2018), cognition and behaviour (Ellis \& Del Giudice, 2019). As a result, they can impact the functioning of these systems later in life (Miller et al., 2011; Smith \& Pollak, 2021).

Compared to people who enjoyed affluent and stable environments during childhood, individuals who grew up in adverse environments are at greater risk of expressing obesity, type 2 diabetes, heart or respiratory diseases, cancers, or autoimmune diseases later in life (Hughes et al., 2017; Miller et al., 2011). Paradoxically, they also produce behaviours that can be equally detrimental for their health: they smoke more (Legleye et al., 2011; Melotti et al., 2011; Nandi et al., 2014), use cannabis (Legleye et al., 2011) and alcohol more (Melotti et al., 2011; Nandi et al., 2014), or exercise less (Nandi et al., 2014). In parallel, early exposure to adverse environments appears to direct individuals toward an urgent need to achieve reproductive goals through physiological and behavioural processes leading to early puberty (Amir et al., 2016), early entry into sexual life and parenthood (Nettle et al., 2011) along with a greater number of children (Nettle, 2010).

An possible explanation for the asymmetry between maintenance and reproductive goals is that of an energy trade-off between these two competing functions (Ellis \& Del Giudice, 2019; Nettle \& Frankenhuis, 2019). This explanation borrows from Life History theory (Del Giudice et al., 2015; Hill \& Kaplan, 1999), a general framework in evolutionary biology that highlights the limited nature of bioenergetic resources and the resulting trade-offs that bind phenotypic traits into patterns of co-variation. It puts forward the idea that investments of resources in reproductive efforts are accompanied by decreases in health efforts on the one hand and direct maintenance costs on the other hand. Ultimately, this pattern would lead to poorer health status later in life and shorter life-expectancy. Interestingly, there may be a notable difference in this pattern between the two sexes (Sear, 2020). For men, poorer health status could be primarily the result of maintenance costs associated with poor health efforts, whereas for women it could additionally be caused by the high metabolic expenditures required by pregnancy and parental care during offspring's early life (Jasienska et al., 2017; Ryan et al., 2018).

Why would adversity lead people to prioritize reproduction and sacrifice their own health and well-being? One possibility is that such a strategy forms the present-oriented end of a behavioural trade-off between present time and future time (Pepper \& Nettle, 2017). Individuals exposed to adversity may have less actual control over their own lives (i.e., external events that cause mortality and morbidity are beyond their control) and thus may prefer acting on a day-to-day basis in order to receive payoffs sooner. This phenomenon, known as "collection risk", describes situations in which waiting for the collection of a later reward - that is, planning for the future is not optimal because it is not certain that you will stay in good enough condition to benefit from it (Stevens \& Stephens, 2010). However, by delaying reward collection, individuals 
potentially expose themselves to "waiting costs", that is, to losing the benefits that could have been accrued in the delay (Mell et al., 2021).

Using either mechanism, this framework predicts that perceived control and time orientation should be key variables mediating the relationships between early life adversity and the trade-off between maintenance and reproduction. Thus, for individuals who have little or no control over events that may affect their lives, the future is uncertain and, therefore, they cannot risk delaying reproduction to invest in activities or functions that are only beneficial in the long run, such as health. Recent findings provide evidence that seem to support this prediction, at least in the health domain. First, the link between life conditions and perceived control - and more broadly locus of control, i.e., the degree to which individuals believe that they, as opposed to external factors such as chance, fate, or other agents, have control over their lives (Rotter, 1966; Lefcourt, 1976) - is well documented. For example, a number of studies have shown that people of lower social class, in possession of fewer resources, exposed to greater instabilities, or in a poorer health status, tend to perceive external, uncontrollable forces and other individuals as the primary causes of events that affect their lives (reviewed in Kraus et al., 2012). In contrast, people with higher socio-economic position perceived themselves (their internal states, motivations and emotions) as the primary causal sources of what happens to them (Kraus et al., 2012). In addition, Pepper and Nettle (2014) found that the effect of individuals' socioeconomic status (SES) on the amount of self-reported health effort was entirely mediated by perceived extrinsic mortality risk. Finally, some recent works suggest that certain adversity factors encountered early in life (e.g., economic scarcity, attachment insecurity) increases mental health problems (e.g., depression, anxiety) later in life via an external locus of control (Culpin et al., 2015; Di Pentima et al., 2019).

To our knowledge, however, no existing studies has yet systematically explored the possibility that early life adversity, perceived control, time orientation, reproductive and maintenance traits all covary in a manner consistent with predictions made by theoretical frameworks inspired by Life History research (Pepper \& Nettle, 2017; Ellis \& Del Giudice, 2019). The present study aims to achieve this goal by conducting two sets of large-scale multivariate models testing the mediating role of perceived control (model set 1) and time orientation (model set 2) in the association between early life adversity and a hypothetical trade-off between reproductive (i.e., timing of reproduction, fertility) and maintenance (i.e., health status) traits. Because these traits are expected to cluster differently between females and males (Sear, 2020), model sets will be run separately for individuals of both sexes. Each model set tests two main hypotheses. Hypothesis 1 suggests that early life adversity is related to the reproduction-maintenance trade-off. Hypothesis 2 suggests that early life adversity influences the reproduction-maintenance trade-off via perceived control (model set 1 ) or time orientation (model set 2). We predict that:

i) Higher levels of early life adversity are associated with a reproduction-maintenance trade-off characterized by greater investment in reproductive activities (i.e., younger age at first reproduction, more children) and poorer health status.

ii) This association is mediated by the individuals' perceived control/time orientation, such that higher levels of adversity decrease the feeling of control individuals have over their own lives/increase present orientation, and diminished control/present orientation in turn increases the need for individuals to put more resources in reproduction and fewer resources in health.

To verify our predictions and test their capacity to generalize to out-of-sample data, we apply multivariate structural equation modelling (Kline, 2015) and stratified k-fold cross-validation (Arlot \& Celisse, 2010) on data from the European Value Study (EVS) and the European Social Survey (ESS). Both are large-scale, cross-national, and longitudinal survey research programs on basic human values. 


\section{Methods}

\subsection{Sample}

The European Values Study (EVS) is a large-scale, cross-national, repeated cross-sectional survey research program on basic human values. Its main topics are family, work, environment, perceptions of life, politics and society, religion and morality and national identity. The study has been conducted in four waves since 1981. We made use of the 4th wave of the survey, which started in 2008 and contains respondents from 46 European countries. The European Social Survey (ESS) is another large, cross-national and longitudinal survey that contains data from 40 countries on attitudes, beliefs and behavioural patterns. We made use of the 9th round of the survey that began in 2018. These survey waves contain data to assess respondents' childhood environments and to calculate the age of birth of their first child, both important life history related variables. From both datasets we removed: respondents without children, respondents with too many missing values ( +2 SDs from sample mean) and respondents with missing values on the age variable, as it cannot be accurately imputed. The final sample of the EVS dataset consisted of 43084 participants (25 341 females; 17743 males). The final sample of the ESS dataset consisted of 31065 participants (17 639 females; 13426 males). Descriptive statistics can be found in the Supplementary Table S1.

\subsection{Missing data}

Multiple imputation techniques were used to preserve sample size and avoid biased estimations of model parameters (see Supplementary Table S2 for the \% of missing values per items). Twenty complete EVS datasets were generated by fully conditional specifications for categorical (logistic regression imputation) and ordinal data (proportional odds model). The mice package of $\mathrm{R}$ was used for imputation (van Buuren \& Groothuis-Oudshoorn, 2011).

\subsection{Multivariate models}

The data were analysed with structural equation modelling (SEM) using the lavaan (Rosseel, 2012) and sem Tools (Jorgensen et al., 2020) packages in R. These models are made up of a 'measurement' model that relates the observed 'indicators' to hypothesized, but unobservable 'latents' and a 'structural' model that relates the latent variables to each other by specifying paths between them. The model we specified involved 2 latent variables: Early life adversity and Reproduction-maintenance trade-off. Additionally, Perceived control and Time orientation were directly measured by a variable of the EVS and ESS, respectively.

In our measurement models, Early life adversity is modelled as an emergent variable rather than a reflective latent variable (Brumbach et al., 2009; Mell et al., 2018; Lettinga et al., 2021). The rationale is that adverse life conditions or events are better conceptualized as factors that are not necessarily correlating with one another, but that all contribute to the cumulative probability of developing a particular outcome. Having been exposed to the death of a parent, having been raised in an economically deprived family or in a family with a low educational background, are factors that increase the probability of experiencing an adverse childhood environment, but that might be experienced relatively independently of each other. In addition, such factors might not contribute equally to the probability of developing a particular outcome. The SEM approach offers the opportunity to handle this problem using unknown weight composites, a procedure which captures the collective effects of a set of causes on a response variable (Grace \& Bollen, 2008). In that case, the composite score is computed via a set of weights whose sum maximizes the amount of variance explained in the dependent variables and thus allows comparing the relative contribution of the hypothesized causes to the overall predictive power of the composite. Here, the latent composite Early life adversity computes weights of 3 indicators based on their 
predictive power on the Reproduction-maintenance trade-off latent variable and the Perceived control / Time orientation variable.

In specifying the models, we chose to consider Perceived control, Time orientation and Health - 3 variables that could be classified as ordinal - as continuous variables because responses measured on Likert scales with five or more points share many properties with continuous data and can occasionally be treated as such (Johnson \& Creech, 1983; Norman, 2010; Sullivan \& Artino, 2013; Zumbo \& Zimmerman, 1993).

\subsubsection{EVS model}

In more detail, the Early life adversity latent was modelled by 3 indicators (see Supplementary Table S2): Economic capital deprivation, Human capital deprivation and Experienced mortality in childhood. The Economic capital deprivation indicator was manually constructed from the respondents' scores on two items. Respondents were given the following context: 'When you think about your parents when you were about 14 years old, could you say whether...'. They were then asked to choose a response among 4 possible (from ' 1 - Yes' to ' 4 - No') on the following 2 statements: 'Parent(s) had problems making ends meet' [variable v014] and 'Parent(s) had problems replacing broken things' [variable v018]. Item scores were recoded and summed such that greater scores indicate greater deprivation in economic capital. The Human capital deprivation indicator was calculated from 6 items from the same question set ('Mother liked to read books' [variable v011], 'Discussed politics with mother' [variable v012], 'Mother liked to follow the news' [variable v013], 'Father liked to read books' [variable v015], 'Discussed politics with father' [variable v016] and 'Father liked to follow the news' [variable v017]), plus 2 items providing information on the education of the respondents' parents ('Highest educational level attained father/mother (8 categories)' [variable v004E/V004R]). Item scores were recoded, z-scored and summed such that greater scores indicate greater deprivation in human capital. The Experienced mortality indicator was manually constructed by summing respondents' scores on the following binary items (Yes/No): 'Experienced: death of father' [variable u005a] and 'Experienced: death of mother' [variable u006a], at a reported age below 14. Item scores were recoded such that greater scores indicate greater mortality. Scores on the Economic capital deprivation, Human capital deprivation and Experienced mortality indicators were $\mathrm{z}$ transformed and normalized to be between 0 and 10 , before entering them into the model.

The Reproduction-maintenance trade-off latent variable was modelled by 3 indicators (see Supplementary Table S2): Age at 1st reproduction (representing the timing of reproduction), Number of children (representing fertility), and Health (representing the maintenance state). The Health indicator was directly measured by the 'State of health (subjective)' [variable a009], asking respondents to answer the following question 'All in all, how would you describe your state of health these days?' by choosing a response among five possible, from ' 1 - Very good' to '5 Very poor'. It is important to note that, although dependent on the subjective perception of the respondents, the subjective state of health is highly correlated with the objective somatic state. More specifically, the subjective assessment of health status predicts morbidity (Barger \& Muldoon, 2006; Goldberg et al., 2001) and mortality (Benyamini \& Idler, 1999; Idler \& Benyamini, 1997) better than some traditional physiological risk factors (Haring et al., 2011; Jylhä et al., 2006). The Number of children indicator was constructed manually by subtracting the 'respondents birth year' [variable x002] from the 'birth year of the first child' [variable x011_02]. The Number of children indicator is directly measured by 'How many children do you have deceased children not included' [variable x011_01]. A residual covariance term was also introduced between the Age at 1st reproduction and Number of children indicators in order to account for the effect of early reproduction on the total number of children reported at the time of the interview. Greater scores on the latent variable indicate a poorer health status, a younger age at 1 st childbirth, and a greater number of children. 
Finally, Perceived control was measured directly by the variable 'How much freedom of choice and control' [variable a173] (see Supplementary Table S2). Respondents were put in the following context: 'Some people feel they have completely free choice and control over their lives, and other people feel that what they do has no real effect on what happens to them.' They then ask to answer the question 'How much freedom of choice and control you feel you have over the way your life turns out?', choosing one value in a ten points scale, from ' 1 - None at all' to ' $10-\mathrm{A}$ great deal'. A greater score on this item therefore indicates a greater sense of control over life events.

Whereas Reproduction-maintenance trade-off was modelled as a latent variable and was scaled by fixing its variance to 1, based on the recommendation of Brumbach et al. (2009). Early life adversity was modelled as a composite latent variable. As composite variables also need to be scaled for identification purposes by fixing the coefficient of one of the causal indicators, Early life adversity was scaled by setting the path from Economic capital deprivation to 1 .

In our structural model, we specified 3 paths: a path between Early life adversity and Perceived control, a path between Perceived control and Reproduction-maintenance trade-off and a path between Early life adversity and Reproduction-maintenance trade-off. This allowed us to test both the direct effect of adversity on allocation trade-offs, its indirect effect mediated by perceived control and the total effect, which is the sum of the direct and indirect effects.

\subsubsection{ESS model}

In this model, the Early life adversity latent was again modelled by the same 3 indicators (see Supplementary Table S2): Economic capital deprivation, Human capital deprivation and Experienced mortality in childhood. The Economic capital deprivation indicator was manually constructed from the respondents' scores on the items: 'Father's employment status when respondent 14' [variable EMPRF14, possible answers from ' 1 - Yes employee' to ' 4 - Dead/absent'], 'Father's occupation when respondent 14' [variable OCCF14B, possible answers from ' 1 - Professional and technical occupations' to ' 9 - Farm worker'] and 'Mother's occupation when respondent 14' [variable OCCF14B, possible answers from ' 1 - Professional and technical occupations' to ' 9 - Farm worker']. The variable 'Mother's employment status when respondent 14' [variable EMPRM14] was also initially considered, however the extremely large number of missing values $(46.77 \%)$ prevented its inclusion. Item scores were recoded, z-scored and summed such that greater scores indicate greater deprivation in economic capital. The Human capital deprivation indicator was manually constructed from the respondents' scores on the following variables: 'Highest educational level attained father' (7 categories) [variable EISCEDF] and 'Highest educational level attained mother' (7 categories) [variable EISCEDM]. Item scores were recoded and summed such that greater scores indicate greater deprivation in human capital. The Experienced mortality in childhood indicator was manually constructed by first creating two new variables by considering 'Dead/absent' responses to the 'Father's employment status when respondent 14' and 'Mother's employment status when respondent $14^{\prime}$ items as indicators of absence. Item scores were recoded and summed such that greater scores indicate greater mortality. Scores on the Economic capital deprivation, Human capital deprivation and Experienced mortality in childhood indicators were $\mathrm{z}$ transformed and normalized to be between 0 and 10, before entering them into the model.

The Reproduction-maintenance trade-off latent was modelled by 3 indicators (see Supplementary Table S2): Health, Age at 1st reproduction and Number of children. The Health indicator was directly measured by Subjective general health [variable HEALTH], an item fully identical to its EVS counterpart. The Number of children indicator was constructed manually by subtracting the respondents birth year [variable YRBRN] from the birth year of their first child [variable FCLDBRN]. The Number of children indicator is directly measured by [variable NBTHCLD]. As for the EVS model, a residual covariance term was introduced between the Age at 1st reproduction and Number of children 
indicators. Greater scores on the latent variable indicate a poorer health status, a younger age at 1 st childbirth, and a greater number of children.

Finally, Time orientation was measured directly by the item 'Plan for future or take each day as it comes' [variable PLNFTR] (see Supplementary Table S2), which provides 11 possible response from ' 0 - I plan for my future as much as possible' to ' 10 - I just take each day as it comes'. A greater score on this item therefore indicates a stronger present orientation.

As for the EVS model, Reproduction-maintenance trade-off was modelled as a latent and was scaled by fixing its variance to 1, and Early life adversity was modelled as a composite latent variable and was scaled by setting the path from Economic capital deprivation to 1.

In our structural model, we specified 3 paths: a path between Early life adversity and Time orientation, a path between Time orientation and Reproduction-maintenance trade-off and a path between Early life adversity and Reproduction-maintenance trade-off. These paths allowed us to test both the direct effect of adversity on allocation trade-offs, its indirect effect mediated by present vs future orientation, and the total effect, which is the sum of the direct and indirect effects.

\subsection{Adjustment variables}

The Health, Age at 1st reproduction, Number of children, Perceived control and Time orientation indicators present in the EVS model and/or the ESS model were adjusted for the effect of the age of the respondents and their level of household income [EVS: variable x047r; ESS: variable HINCTNTA] reported at the time of the interview (see Supplementary Table S2).

\subsection{Fitting procedure}

The models were fitted using a weighed least squares estimator (WLSMV) because of its robustness to deviations from normality. Model fit was assessed by the $\chi 2$, CFI, RMSEA and SRMR statistics. All these indicators are summary statistics of 50 individual fits obtained during cross-validation (see below). The $\chi 2$, CFI, RMSEA and SRMR statistics were corrected by a scaling factor which compensates for the average kurtosis of the data (Satorra \& Bentler, 2001). A model's fit is generally considered excellent when the RMSEA is close to 0.05 , the CFI close to 0.95 and SRMR close to 0.08 (Hu \& Bentler, 1999).

The same model was fitted separately for male and female respondents' data to compare the hypothesized relationships between genders. We will refer to these as the male and female models, respectively.

Importantly, for the ESS dataset only, there are survey weights that needed to be incorporated to correct for estimates, standard errors, and chi-square-derived fit measures for the complex sampling design. We followed the recommended weighting procedure in $\mathrm{R}$ by the ESS methodological

guide

(https://www.europeansocialsurvey.org/docs/methodology/ESS_weighting_data_1_1.pdf). We then created a custom $\mathrm{R}$ script based on the lavaan.survey package to fit our model. For more details on this procedure, see Oberski (2014).

\subsection{Cross-validation algorithm}

To address the problem of overfitting due to the inherent complexity of SEM models (Breckler, 1990; Preacher, 2006; Roberts \& Pashler, 2000), we employed a stratified k-fold cross-validation strategy (Arlot \& Celisse, 2010). The aim of applying stratified $k$-fold cross-validation to SEM is twofold. First, it submits a model to sampling variability and therefore allows to estimate its stability across multiple reshuffling and re-stratification of the data sample. Second, it tests the 
capacity of a model to generalize its predictions to out-of-sample data. The analyses consisted of the following steps:

1. The full data set is randomly partitioned into 5 folds of nearly equal size.

2. Subsequently 5 iterations of training and validation are performed such that within each iteration a different fold of the data is held-out for validation (the test data, here representing $20 \%$ of the whole sample) while the remaining $k-1$ folds are used for fitting (the training data, here representing $80 \%$ of the whole sample).

3. At each iteration, the model is fitted on the training data, and then its parameters are set according to these results. After that, it is re-fitted on the test data.

4. The predictive value of the training model is further checked by applying the same crossvalidation procedure on a test dataset whose individual values have been randomly permuted within each indicator. The aim is to ensure that the fitted values obtained from modelling the training data failed at predicting the test data when its internal structure is broken down by means of randomization. In other words, this procedure allows us to state whether the latent structure hypothesized by our structural equation model is present or absent in the training samples.

5. At the end of the 5 iterations, the whole sample is reshuffled and re-stratified before a new round of 5 iterations starts.

6. The whole procedure is repeated 10 times (10 rounds of 5 iterations, meaning overall 50 iterations) in order to obtain reliable performance estimation (the mean and standard deviations across iterations of the predictive accuracy ratio). Note that at each iteration within a round, the training and the test datasets always include different data points.

\subsection{Reporting of the results}

Cross-validated goodness-of-fit indices for a given model are expressed in terms of the median on the testing data. Similarly, the goodness-of-fit indices of a given model are expressed in terms of the median on the training. Finally, parameters estimates obtained from the measurement and the structural parts of a given model fitted on the training set over the 50 iterations are expressed in term of the median. The reason is that medians are best suited to account for a model's precision in the present context: the distributions of values are often skewed because of the sampling variability resulting from the multiple re-shuffling and re-stratification of data during the cross-validation procedure. Comparisons were made by using Wilcoxon rank sum tests. Finally, to enhance the readability of the text, all statistical indices and parameter estimates corroborating the description of the models are reported in the tables included in the main text and in the Supplementary Information. The cross-validated median goodness-of-fit indices are reported in Tables 1 and 2. The median parameter estimates of their 'measurement' and 'structural' parts are reported in Table 3 for the EVS dataset, and Table 4 for the ESS dataset.

\subsection{Visualizing the models}

Visualizing the modelled individual latent scores is difficult because in our cross-validation strategy, the dataset at each iteration has a different number and identity of subjects. Therefore, simply averaging across iterations is impossible. So, we resorted to ignoring cross-validation for visualization purposes and merely estimated the model on each imputation. Then, we used the lavaanPredict function to extract the modelled variable scores for each subject. Finally, we averaged these results across the 20 imputed datasets. The associations between the Early life adversity scores and the Perceived control/Time orientation scores, so as the associations between the Perceived 
control/Time orientation scores and the Reproduction-maintenance trade-off latent scores were visualized in Supplementary Figures S1 and S2.

\section{Results}

\subsection{EVS dataset}

\subsubsection{Cross-validated goodness of fit}

Both the male and female models provided an excellent fit. This is supported by scaled CFI values $>.95$, RMSEA values $<.05$, and SRMR values $<.08$ on the test dataset (Table 1 and Figure 1.a). These results indicate that the discrepancies between the observed covariance matrices on the test data and the model-implied covariance matrices on the training data were minimal (RMSEA), and that the models performed better than their null versions including only the variance of the indicators as parameters fitted on the test data (CFI, SRMR). This is also corroborated by the random fits, which show the degree to which the models failed to predict test data whose internal structure was decomposed using random permutations. The model fits

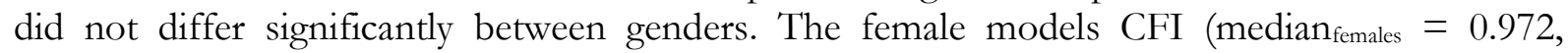
median $_{\text {males }}=0.970$, Wilcoxon $\left.\mathrm{W}=1138, \mathrm{p}=.165\right)$ and SRMR (median females $_{\text {f }}=0.021$, median $_{\text {males }}$ $=0.020$, Wilcoxon $\mathrm{W}=1354, \mathrm{p}=.992)$ indices were not statistically different from their respective counterparts in the male models. However, they did have a higher RMSEA $\left(\right.$ median $_{\text {females }}=0.022$, median $_{\text {males }}=0.020$, Wilcoxon $\left.\mathrm{W}=954, \mathrm{p}=.010\right)$.

\begin{tabular}{ll|ll}
\hline Data & Index & EVS Male model & EVS Female model \\
\hline \multirow{4}{*}{ Training } & $\chi^{2}$ & $188.684(12.190)$ & $340.798(17.489)$ \\
& CFI & $0.964(0.003)$ & $0.965(0.002)$ \\
& RMSEA & $0.038(0.001)$ & $0.043(0.001)$ \\
& SRMR & $0.016(<0.001)$ & $0.018(0.001)$ \\
\multirow{4}{*}{ Test } & $\chi^{2}$ & $63.966(15.528)$ & $87.626(14.718)$ \\
& CFI & $0.970(0.012)$ & $0.972(0.007)$ \\
& RMSEA & $0.020(0.004)$ & $0.022(0.003)$ \\
\multirow{4}{*}{ Random } & SRMR & $0.020(0.003)$ & $0.021(0.002)$ \\
& $\chi 2$ & $783.909(50.387)$ & $1284.649(58.340)$ \\
& CFI & $0.000(0.000)$ & $0.000(0.000)$ \\
& RMSEA & $0.091(0.003)$ & $0.098(0.003)$ \\
& SRMR & $0.072(0.003)$ & $0.077(0.002)$ \\
\hline
\end{tabular}

Table 1. EVS models. Stratified 5-fold cross-validation. Values are medians over 50 iterations, values in brackets are median absolute deviations.

\subsubsection{Male model parameters}

In the male model (Table 2, Figures 1.b and 1.c), the measurement model indicates that the composite Early life adversity impacts the other variables in the model primarily via Human capital deprivation and Economic capital deprivation. Experienced mortality only contributes marginally to the predictive power of the composite. The Reproduction-maintenance trade-off latent variable positively correlates with the Health indicator and, to a lesser extent, negatively with the Age at 1st reproduction indicator, showing that male respondents with higher scores on this latent also report a poorer health status and reproduce earlier. Number of children on the other hand has no relationship with 
the latent. The structural model further indicates that Early life adversity is significantly and negatively related to Perceived control, meaning that in men, experiencing higher levels of early adversity is associated with a reduced sense of control over life events as an adult. Perceived control is also significantly and negatively related to the Reproduction-maintenance trade-off latent, suggesting that in men, a lower sense of control is associated with greater investments in reproduction to the detriment of health. Combining the above two, the estimate of the total and indirect effect of Early life adversity on Reproduction-maintenance trade-off indicates that the indirect effect is significant but accounts for a small portion of the total effect $(\sim 8.4 \%)$.

\begin{tabular}{|c|c|c|c|c|c|c|c|c|c|}
\hline \multicolumn{10}{|c|}{ EVS Male model } \\
\hline Model part & Latent variables & & Indicators & $\begin{array}{l}\text { Unstd. } \\
\text { est. }\end{array}$ & CI & se & $\mathbf{z}$ & $\mathrm{p}$ & $\begin{array}{l}\text { Std. } \\
\text { est. }\end{array}$ \\
\hline \multirow{6}{*}{$\begin{array}{l}\text { Measurement } \\
\text { model }\end{array}$} & Early life adversity & $<\sim$ & $\begin{array}{l}\text { Economic capital } \\
\text { deprivation }\end{array}$ & 1.000 & {$[1.000,1.000]$} & 0 & - & - & .660 \\
\hline & Early life adversity & $<\sim$ & $\begin{array}{l}\text { Human capital } \\
\text { deprivation }\end{array}$ & 1.429 & {$[1.082,1.779]$} & 0.179 & 7.99 & $<.001$ & .599 \\
\hline & Early life adversity & $<\sim$ & $\begin{array}{l}\text { Experienced } \\
\text { childhood mortality }\end{array}$ & 0.417 & {$[-0.018,0.873]$} & 0.226 & 1.88 & .060 & .094 \\
\hline & $\begin{array}{l}\text { Reproduction- } \\
\text { maintenance trade-off }\end{array}$ & $=\sim$ & Health & 0.399 & {$[0.333,0.467]$} & 0.034 & 11.83 & $<.001$ & .475 \\
\hline & $\begin{array}{l}\text { Reproduction- } \\
\text { maintenance trade-off }\end{array}$ & $=\sim$ & $\begin{array}{l}\text { Age at } 1 \text { st } \\
\text { reproduction }\end{array}$ & -0.086 & {$[-0.100,-0.072]$} & 0.007 & -12.08 & $<.001$ & -.181 \\
\hline & $\begin{array}{l}\text { Reproduction- } \\
\text { maintenance trade-off }\end{array}$ & $=\sim$ & Number of children & 0.013 & {$[-0.018,0.045]$} & 0.016 & 0.83 & .405 & .013 \\
\hline \multirow{5}{*}{$\begin{array}{l}\text { Structural } \\
\text { model }\end{array}$} & (a) Perceived control & $\sim$ & Early life adversity & -0.041 & {$[-0.050,-0.032]$} & 0.005 & -8.88 & $<.001$ & -.095 \\
\hline & $\begin{array}{l}\text { (b) Reproduction- } \\
\text { maintenance trade-off }\end{array}$ & $\sim$ & Perceived control & -0.123 & {$[-0.147,-0.099]$} & 0.013 & -9.80 & $<.001$ & -.261 \\
\hline & $\begin{array}{l}\text { (c) Reproduction- } \\
\text { maintenance trade-off }\end{array}$ & $\sim$ & Early life adversity & 0.059 & {$[0.046,0.072]$} & 0.007 & 8.96 & $<.001$ & .294 \\
\hline & Indirect effect & $:=$ & $\mathrm{a} * \mathrm{~b}$ & 0.005 & {$[0.004,0.006]$} & 0.001 & 6.59 & $<.001$ & .025 \\
\hline & Total effect & $:=$ & $\mathrm{c}+(\mathrm{a} * \mathrm{~b})$ & 0.064 & {$[0.050,0.078]$} & 0.007 & 44452 & $<.001$ & .319 \\
\hline \multicolumn{10}{|c|}{ EVS Female model } \\
\hline Model part & Latent variables & & Indicators & $\begin{array}{l}\text { Unstd. } \\
\text { est. }\end{array}$ & CI & se & $\mathrm{z}$ & $\mathrm{p}$ & $\begin{array}{l}\text { Std. } \\
\text { est. }\end{array}$ \\
\hline \multirow{6}{*}{$\begin{array}{l}\text { Measurement } \\
\text { model }\end{array}$} & Early life adversity & $<\sim$ & $\begin{array}{l}\text { Economic capital } \\
\text { deprivation }\end{array}$ & 1.000 & {$[1.000,1.000]$} & 0 & - & - & .597 \\
\hline & Early life adversity & $<\sim$ & $\begin{array}{l}\text { Human capital } \\
\text { deprivation }\end{array}$ & 1.797 & {$[1.549,2.052]$} & 0.130 & 13.82 & $<.001$ & .675 \\
\hline & Early life adversity & $<\sim$ & $\begin{array}{l}\text { Experienced } \\
\text { childhood mortality }\end{array}$ & 0.187 & {$[-0.081,0.459]$} & 0.138 & 1.38 & .169 & .041 \\
\hline & $\begin{array}{l}\text { Reproduction- } \\
\text { maintenance trade-off }\end{array}$ & $=\sim$ & Health & 0.285 & {$[0.251,0.317]$} & 0.017 & 16.77 & $<.001$ & .360 \\
\hline & $\begin{array}{l}\text { Reproduction- } \\
\text { maintenance trade-off }\end{array}$ & $=\sim$ & $\begin{array}{l}\text { Age at } 1 \text { st } \\
\text { reproduction }\end{array}$ & -0.108 & {$[-0.121,-0.095]$} & 0.007 & -16.44 & $<.001$ & -.268 \\
\hline & $\begin{array}{l}\text { Reproduction- } \\
\text { maintenance trade-off }\end{array}$ & $=\sim$ & Number of children & 0.095 & {$[0.072,0.119]$} & 0.012 & 7.92 & $<.001$ & .101 \\
\hline \multirow{5}{*}{$\begin{array}{l}\text { Structural } \\
\text { model }\end{array}$} & (a) Perceived control & $\sim$ & Early life adversity & -0.042 & {$[-0.049,-0.036]$} & 0.003 & -12.41 & $<.001$ & -.110 \\
\hline & $\begin{array}{l}\text { (b) Reproduction- } \\
\text { maintenance trade-off }\end{array}$ & $\sim$ & Perceived control & -0.116 & {$[-0.137,-0.095]$} & 0.011 & -10.98 & $<.001$ & -.220 \\
\hline & $\begin{array}{l}\text { (c) Reproduction- } \\
\text { maintenance trade-off }\end{array}$ & $\sim$ & Early life adversity & 0.104 & {$[0.089,0.119]$} & 0.008 & 13.38 & $<.001$ & .510 \\
\hline & Indirect effect & $:=$ & $\mathrm{a} * \mathrm{~b}$ & 0.005 & {$[0.004,0.006]$} & 0.001 & 8.29 & $<.001$ & .024 \\
\hline & Total effect & $:=$ & $\mathrm{c}+(\mathrm{a} * \mathrm{~b})$ & 0.109 & {$[0.093,0.124]$} & 0.008 & 13.51 & $<.001$ & .534 \\
\hline
\end{tabular}

Table 2. EVS models. Parameter estimates. We also report under the $\mathrm{z}$ label values of Wald tests (and their $\mathrm{p}$ values) as indicators of simple effect sizes. All values are medians over 50 iterations. 


\subsubsection{Female model parameters}

In the female model (Table 2, Figures 1.b and 1.d), the measurement part indicates that the effect of the composite Early life adversity on the other variables of the model is primarily driven by Human capital deprivation and Economic capital deprivation. The contribution of Experienced mortality, on the other hand, is almost null. As for the male model, the Reproduction-maintenance trade-off latent variable correlates positively with the Health indicator and negatively with the Age at 1st reproduction indicator. However, unlike the male model, the strength of these two correlations is more homogeneous. In addition, the Number of children indicator also correlates significantly and positively on the latent. Therefore, female respondents who score high on the latent Reproductionmaintenance trade-off report poorer health, reproduce earlier and have more children. The structural part of the female model indicates that Early life adversity is significantly and negatively related to Perceived control, meaning that in women, higher levels of early adversity are associated with a reduced sense of control over their own lives. Perceived control is also significantly and negatively related to the Reproduction-maintenance trade-off latent, suggesting that in women, a lower sense of control is associated with greater investments in reproduction to the detriment of health. Combining the above two, the estimate of the total and indirect effect of Early life adversity on Reproduction-maintenance trade-off indicates that the indirect effect is significant but accounts for a small portion of the total effect $(\sim 4.5 \%)$. Comparing the male and female models reveals that all effects point in the same direction in both models. In the female model however, the relationship between the latent constructs and their indicators, as well as the relationships between these constructs, are stronger (or are equally strong) relative to the male model.

a. EVS models. Cross-validated fit indices
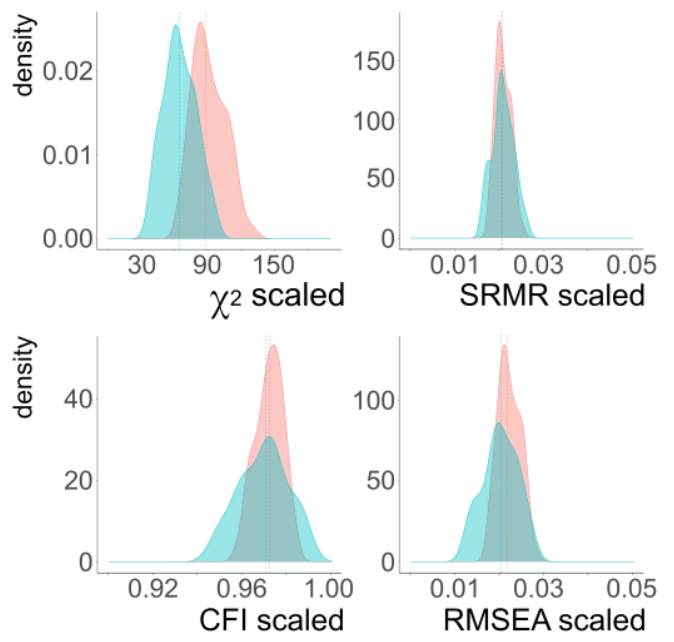

c. EVS male model. Training data
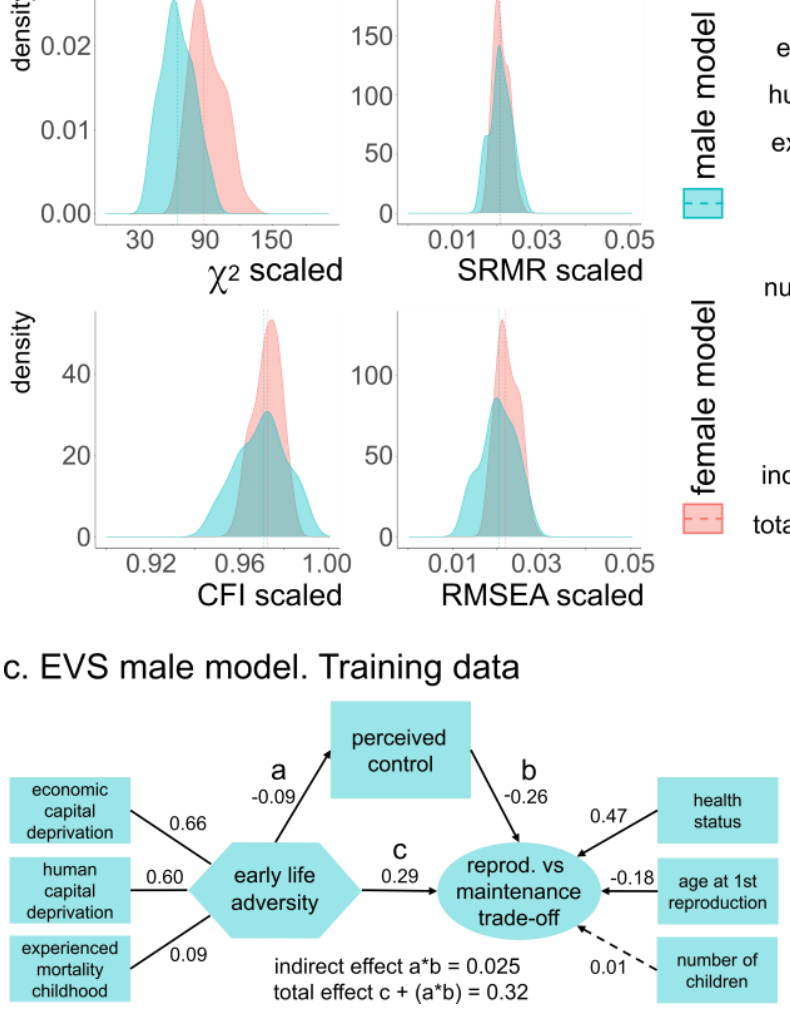

b. EVS models. std coeff and $p$ values proba densities
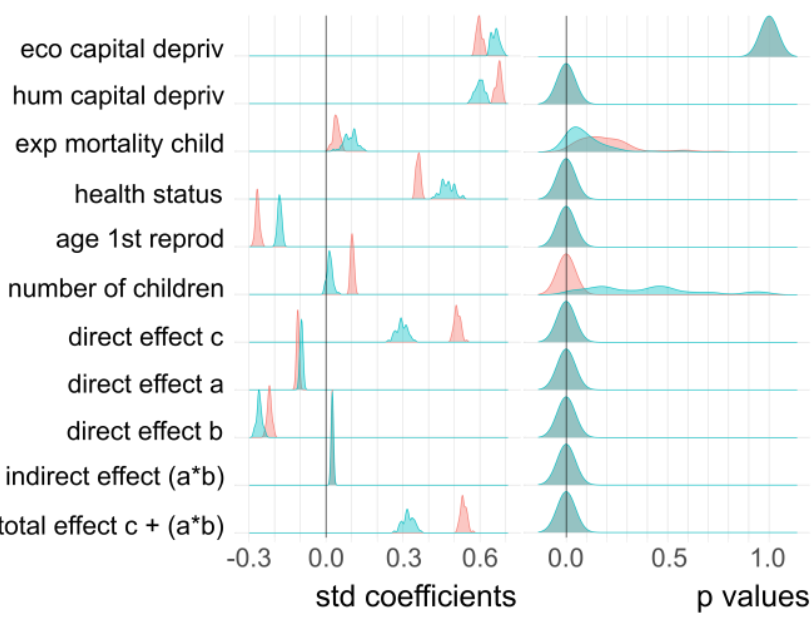

d. EVS female model. Training data

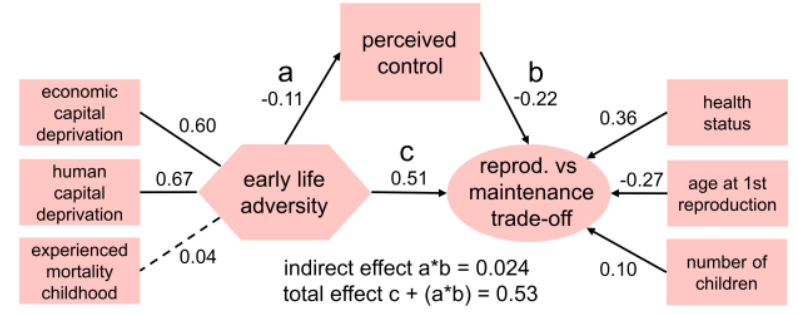

Figure 1. EVS models. Main results. a. Distributions of the goodness-of-fit indices of the male and female models cross-validated on the test datasets. Vertical lines indicate the median. b. Distributions of the standardized coefficients and associated $p$ values of the indicators (see rectangles in panel C) estimated from fitting the model to the training datasets. c.d. Structures and standardized parameters (median values) of the male (c) and female (d) models estimated from fitting the training datasets. Ellipses represent latent variables, rectangles represent their indicators, composite variables and direct measures. Significant paths are represented by bold lines and arrows. 


\subsection{ESS dataset}

\subsubsection{Cross-validated goodness of fit}

Both the male and female models provide an excellent fit. This is supported by scaled CFI values $>.95$, RMSEA values $<.05$, and SRMR values $<.08$ on the test dataset (Table 3 and Figure 2.a). These results indicate that the discrepancies between the observed covariance matrices on the test data and the model-implied covariance matrices on the training data are minimal (RMSEA), and that the models performed better than their null versions including only the variance of the indicators as parameters fitted on the test data (CFI, SRMR). This is also corroborated by the random fits, which show the degree to which models fail at predicting test data whose internal structure is broken down by means of random permutations. The model fits are overall better for

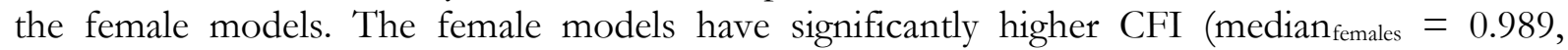
median $_{\text {males }}=0.971$, Wilcoxon W $\left.=613, \mathrm{p}<.001\right)$, lower SRMR $\left(\right.$ median $_{\text {females }}=0.025$, median $_{\text {males }}$ $=0.022$, Wilcoxon $\mathrm{W}=2031, \mathrm{p}<.001)$ and RMSEA indices $\left(\right.$ median $_{\text {females }}=0.010$, median $_{\text {males }}=$ 0.014, Wilcoxon $\mathrm{W}=1883, \mathrm{p}<.001)$.

\begin{tabular}{ll|ll}
\hline Data & Index & ESS Male model & ESS Female model \\
\hline \multirow{4}{*}{ Training } & $\chi^{2}$ & $22.109(5.225)$ & $21.525(4.508)$ \\
& CFI & $0.993(0.003)$ & $0.996(0.001)$ \\
& RMSEA & $0.012(0.002)$ & $0.010(0.002)$ \\
& SRMR & $0.009(0.001)$ & $0.007(0.001)$ \\
\multirow{4}{*}{ Test } & $\chi^{2}$ & $40.409(13.522)$ & $36.085(10.366)$ \\
& CFI & $0.971(0.021)$ & $0.989(0.010)$ \\
& RMSEA & $0.014(0.007)$ & $0.010(0.006)$ \\
\multirow{4}{*}{ Random } & SRMR & $0.025(0.004)$ & $0.022(0.003)$ \\
& $\chi 2$ & $365.720(61.269)$ & $522.518(71.897)$ \\
& CFI & $0.000(0.000)$ & $0.000(0.000)$ \\
& RMSEA & $0.070(0.007)$ & $0.074(0.006)$ \\
& SRMR & $0.075(0.005)$ & $0.081(0.004)$ \\
\hline
\end{tabular}

Table 3. ESS models. Stratified 5-fold cross-validation. Values are medians over 50 iterations, values in brackets are median absolute deviations.

\subsubsection{Male model parameters}

In the male model (Table 4, Figures 2.b and 2.c), the measurement model shows that none of the 3 indicators of the composite Early life adversity has a convincing predictive weight on the other variables of the model. However, the Reproduction-maintenance trade-off latent variable shows a good consistency in this male model, with respect to its EVS counterpart. Indeed, the latent correlates positively with the Health indicator, negatively with the Age at 1st reproduction indicator, and positively with the Number of children indicator. Therefore, male respondents who score high on the latent Reproduction-maintenance trade-off report a poorer health, reproduced earlier, and have more children. The structural model confirms that Early life adversity is not significantly related to either Time orientation or Reproduction-maintenance trade-off. It shows however that Time orientation is significantly and positively related to the Reproduction-maintenance trade-off latent, suggesting that in men, more present orientation is associated with greater investments in reproduction to the detriment of health. Given the complete absence of effects of Early life adversity in this model, the indirect and total effects are not discussed. 


\begin{tabular}{|c|c|c|c|c|c|c|c|c|c|}
\hline \multicolumn{10}{|c|}{ ESS Male model } \\
\hline Model part & Latent variables & & Indicators & $\begin{array}{l}\text { Unstd. } \\
\text { est. }\end{array}$ & CI & se & $\mathrm{z}$ & $\mathrm{p}$ & $\begin{array}{l}\text { Std. } \\
\text { est. }\end{array}$ \\
\hline \multirow{6}{*}{$\begin{array}{l}\text { Measurement } \\
\text { model }\end{array}$} & Early life adversity & $<\sim$ & $\begin{array}{l}\text { Economic capital } \\
\text { deprivation }\end{array}$ & 1.000 & {$[1.000,1.000]$} & 0 & - & - & .357 \\
\hline & Early life adversity & $<\sim$ & $\begin{array}{l}\text { Human capital } \\
\text { deprivation }\end{array}$ & 1.127 & {$[-0.429,2.722]$} & 0.787 & 1.42 & .155 & .572 \\
\hline & Early life adversity & $<\sim$ & $\begin{array}{l}\text { Experienced } \\
\text { childhood mortality }\end{array}$ & 1.801 & {$[-0.295,3.685]$} & 0.993 & 1.66 & .098 & .562 \\
\hline & $\begin{array}{l}\text { Reproduction- } \\
\text { maintenance trade-off }\end{array}$ & $=\sim$ & Health & 0.128 & {$[0.069,0.193]$} & 0.031 & 4.33 & $<.001$ & .164 \\
\hline & $\begin{array}{l}\text { Reproduction- } \\
\text { maintenance trade-off }\end{array}$ & $=\sim$ & $\begin{array}{l}\text { Age at } 1 \text { st } \\
\text { reproduction }\end{array}$ & -0.123 & {$[-0.186,-0.061]$} & 0.032 & -3.85 & $<.001$ & -.248 \\
\hline & $\begin{array}{l}\text { Reproduction- } \\
\text { maintenance trade-off }\end{array}$ & $=\sim$ & Number of children & 0.162 & {$[0.064,0.258]$} & 0.050 & 3.19 & .001 & .176 \\
\hline \multirow{5}{*}{$\begin{array}{l}\text { Structural } \\
\text { model }\end{array}$} & (a) Time orientation & $\sim$ & Early life adversity & 0.024 & {$[-0.006,0.054]$} & 0.015 & 1.55 & .122 & .041 \\
\hline & $\begin{array}{l}\text { (b) Reproduction- } \\
\text { maintenance trade-off }\end{array}$ & $\sim$ & Time orientation & 0.098 & {$[0.041,0.147]$} & 0.027 & 3.39 & $<.001$ & .259 \\
\hline & $\begin{array}{l}\text { (c) Reproduction- } \\
\text { maintenance trade-off }\end{array}$ & $\sim$ & Early life adversity & 0.068 & {$[-0.009,0.145]$} & 0.040 & 1.72 & .086 & .300 \\
\hline & Indirect effect & $:=$ & $\mathrm{a} * \mathrm{~b}$ & 0.002 & {$[0.000,0.006]$} & 0.002 & 1.41 & .158 & .010 \\
\hline & Total effect & $:=$ & $\mathrm{c}+(\mathrm{a} * \mathrm{~b})$ & 0.070 & {$[-0.009,0.151]$} & 0.041 & 1.73 & .084 & .314 \\
\hline \multicolumn{10}{|c|}{ ESS Female model } \\
\hline Model part & Latent variables & & Indicators & $\begin{array}{l}\text { Unstd. } \\
\text { est. }\end{array}$ & CI & se & z & $\mathrm{p}$ & $\begin{array}{l}\text { Std. } \\
\text { est. }\end{array}$ \\
\hline \multirow{6}{*}{$\begin{array}{l}\text { Measurement } \\
\text { model }\end{array}$} & Early life adversity & $<\sim$ & $\begin{array}{l}\text { Economic capital } \\
\text { deprivation }\end{array}$ & 1.000 & {$[1.000,1.000]$} & 0 & - & - & .416 \\
\hline & Early life adversity & $<\sim$ & $\begin{array}{l}\text { Human capital } \\
\text { deprivation }\end{array}$ & 1.101 & {$[0.400,1.771]$} & 0.349 & 3.10 & .002 & .652 \\
\hline & Early life adversity & $<\sim$ & $\begin{array}{l}\text { Experienced } \\
\text { childhood mortality }\end{array}$ & 0.990 & {$[0.339,1.647]$} & 0.331 & 2.92 & .003 & .380 \\
\hline & $\begin{array}{l}\text { Reproduction- } \\
\text { maintenance trade-off }\end{array}$ & $=\sim$ & Health & 0.173 & {$[0.134,0.212]$} & 0.020 & 8.68 & $<.001$ & .213 \\
\hline & $\begin{array}{l}\text { Reproduction- } \\
\text { maintenance trade-off }\end{array}$ & $=\sim$ & $\begin{array}{l}\text { Age at } 1 \text { st } \\
\text { reproduction }\end{array}$ & -0.184 & {$[-0.230,-0.140]$} & 0.023 & -7.99 & $<.001$ & -.400 \\
\hline & $\begin{array}{l}\text { Reproduction- } \\
\text { maintenance trade-off }\end{array}$ & $=\sim$ & Number of children & 0.198 & {$[0.128,0.267]$} & 0.035 & 5.57 & $<.001$ & .208 \\
\hline \multirow{5}{*}{$\begin{array}{l}\text { Structural } \\
\text { model }\end{array}$} & (a) Time orientation & $\sim$ & Early life adversity & 0.033 & {$[0.010,0.057]$} & 0.012 & 2.76 & .006 & .049 \\
\hline & $\begin{array}{l}\text { (b) Reproduction- } \\
\text { maintenance trade-off }\end{array}$ & $\sim$ & Time orientation & 0.087 & {$[0.058,0.115]$} & 0.014 & 5.96 & $<.001$ & .228 \\
\hline & $\begin{array}{l}\text { (c) Reproduction- } \\
\text { maintenance trade-off }\end{array}$ & $\sim$ & Early life adversity & 0.097 & {$[0.050,0.144]$} & 0.024 & 3.99 & $<.001$ & .366 \\
\hline & Indirect effect & $:=$ & $\mathrm{a} * \mathrm{~b}$ & 0.003 & {$[0.001,0.005]$} & 0.001 & 2.49 & .013 & .011 \\
\hline & Total effect & $:=$ & $\mathrm{c}+(\mathrm{a} * \mathrm{~b})$ & 0.100 & {$[0.052,0.148]$} & 0.025 & 4.01 & $<.001$ & .378 \\
\hline
\end{tabular}

Table 4. ESS models. Parameter estimates. We also report under the z label values of Wald tests (and their $\mathrm{p}$ values) as indicators of simple effect sizes. All values are medians over 50 iterations.

\subsubsection{Female model parameters}

In the female model (Table 4, Figures 2.b and 2.d), the measurement part indicates that the predictive power of the composite Early life adversity is driven by Human capital deprivation, Economic capital deprivation and Experienced mortality to similar extents. As for the male model, the Reproduction-maintenance trade-off correlates in a consistent way with each of its 3 indicators as well. Indeed, female respondents who score high on this latent report a poorer health, reproduced earlier, and have more children. The structural model further indicates that Early life adversity is 
significantly and positively related to Time orientation, meaning that in women, greater levels of adversity are associated with a more present oriented worldview. Time orientation is also significantly and positively related to the Reproduction-maintenance trade-off latent, suggesting that in women, a stronger orientation towards the present is associated with greater investments in reproduction to the detriment of health. Putting the above two together, the estimation of the total and indirect effect of Early life adversity on Reproduction-maintenance trade-off indicates that the indirect effect is significant but represents a small part of the total effect $(\sim 2.9 \%)$. Overall, comparing the male and female models reveals that most effects point in the same direction. The female model, however, overall has larger or equal effect sizes in all relationships. This is true both for the measurement and structural models.

a. ESS models. Cross-validated fit indices
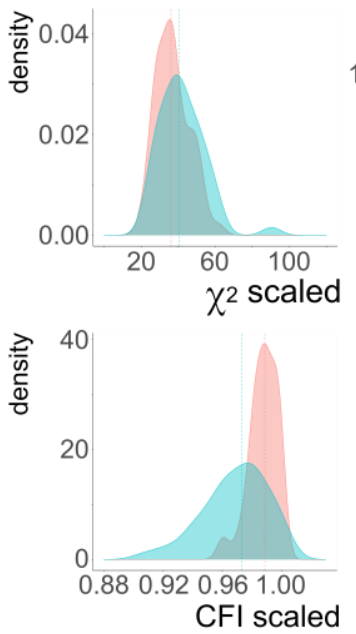
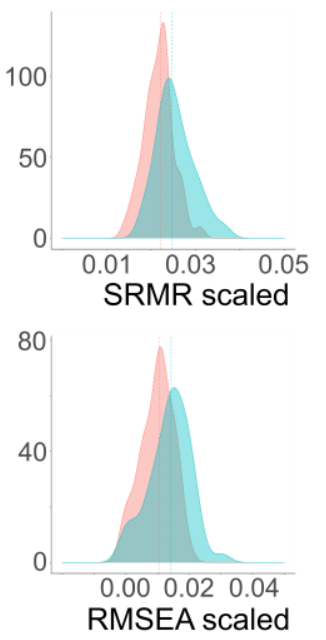

b. ESS models. std coeff and $p$ values proba densities
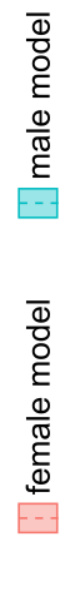

c. ESS male model. Training data

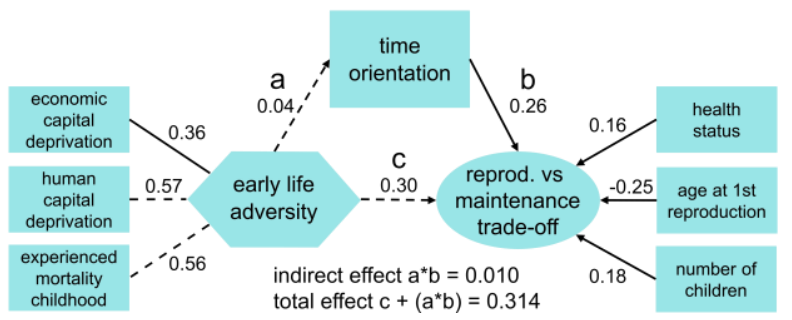

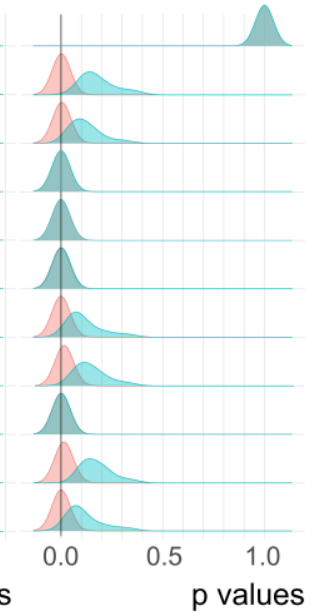

d. ESS female model. Training data

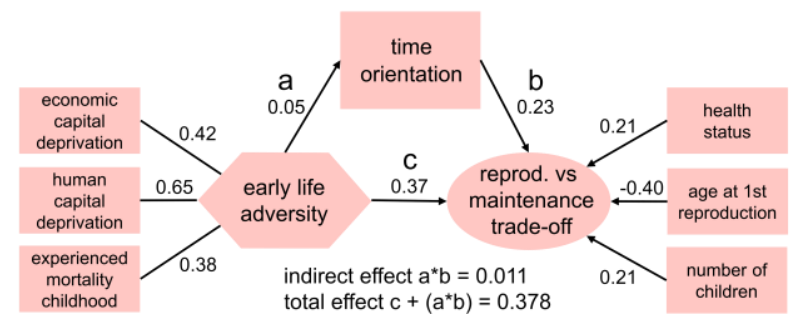

Figure 2. ESS models. Main results. a. Distributions of the goodness-of-fit indices of the male and female models cross-validated on the test datasets. Vertical lines indicate the median. b. Distributions of the standardized coefficients and associated $p$ values of the indicators (see rectangles in panel C) estimated from fitting the model to the training datasets. c.d. Structures and standardized parameters (median values) of the male (c) and female (d) models estimated from fitting the training datasets. Ellipses represent latent variables, rectangles represent their indicators, composite variables and direct measures. Significant paths are represented by bold lines and arrows.

\section{Discussion}

In this study, we investigated two psychological traits - perceived control and time orientation that possibly mediate the effect of early life adversity on reproductive behaviour and health status. To do so, we made use of a cross-validated structural equation modelling analysis on a large, public survey database, the European Values Survey (EVS). Confirming previous studies (Brumbach et al., 2009; Mell et al., 2018; Nettle, 2011), we found that deprivation in human and economic capital is associated with poorer health, earlier reproduction and higher overall number of children. Importantly, our models also revealed a moderate effect of perceived control on the shape of a hypothetical trade-off between reproductive and maintenance traits. However, the 
effect of early life adversity on the perceived control was small (of note is that the effect of current income was even smaller). The effect of current income on this psychological trait was of a similar magnitude, suggesting that its primary determinant is of a different nature than the ecological factors (past or current) that we used here (e.g., genetic makeup). As a consequence, we only found weak support for our main hypothesis: each unit increase in perceived control score had only an anecdotal effect on the strength of the positive association between adverse childhood conditions and the reproduction-maintenance trade-off. Interestingly, a similar set of results emerged from the application of the same cross-validated SEMs to the independent dataset of the European Social Study, with time orientation taken as the mediator of the association between early life adversity and the reproduction-maintenance trade-off. At least in the female sample, adverse childhood environments were weakly associated with a presentoriented worldview (a moderate negative effect of current income was however detected: median std.coeff $=-0.18$; median $\mathrm{p}<.001$ ), which in turn was moderately associated with the reproduction-maintenance trade-off described above. However, the mediating effect of time orientation in the association between early life adversity and the reproduction-maintenance trade-off is again anecdotal. In the male sample, these effects were simply absent.

Contrary to our initial hypotheses, these results suggest that early life adversity, perceived control and time orientation impact reproductive timing, fertility and health status in a relatively independent manner. This is mainly due to the fact that perceived control and time orientation are weakly associated with our early life adversity latent factor. A possible explanation of these marginal associations is that the way perceived control and time orientation are measured here could be too simplistic to accurately represent such complex psychological constructs. For example, some authors (Shapiro et al., 1993) argue that perceived control (as well as time orientation, Zimbardo \& Boyd, 1999) might be better conceptualized as a combination of several dimensions such as locus of control (i.e., the degree to which individuals believe that they, as opposed to external factor such as chance or other agents, have control over their lives, Rotter, 1966; Lefcourt, 1976), self-efficacy (i.e., a person's ability to cope with a given situation based on the skills he or she possesses and the circumstances he or she faces, Bandura, 1977), learned helplessness (i.e., acceptance of powerlessness after repeated exposure to harsh events, Maier \& Seligman, 1976), and desire of control. In other words, a more precise measure of perceived control and time orientation might have increased our chance of detecting an association between these constructs and early life adversity, an association often reported in the literature (Krauss et al., 2012; Culpin et al., 2015; Pepper e Nettle, 2017; Di Pentima et al., 2019). Nevertheless, this explanation is challenged by the robust associations we found between perceived control and time orientation with the reproduction maintenance trade-off. An alternative explanation of the marginal associations described above is that they represent the visible end of broader correlations encompassing higher levels of adversity than those found in the Western, industrialized, and affluent countries that comprise our two datasets. If this is true, running our models on more diverse samples could help validate our initial hypotheses.

Other interesting features of our results are worth discussing. First, while human and economic capital deprivation indicators were robustly associated with our latent composite adversity, experienced mortality was not (the only exception was with the ESS female model). Previous studies have shown mortality to be similarly associated with other adversity variables (Mell et al., 2018). This could be the result of relatively little variation in this measure in the industrialized and affluent European countries that constitute the EVS dataset. Furthermore, our extrinsic mortality variable is indexed to the loss of the respondents' parents, which provides a very restricted view of what the true extrinsic mortality rate really is. Alternatively, there may be a meaningful dissociation between the economic and social variables that we found to be robustly associated with the latent on the one hand, and experienced mortality that was not associated with the latent on the other. One important difference is that mortality is a more objective measure, whereas the 
other variables we used reflect more subjective judgments about relative deprivation. Interestingly, a recent study found that subjective indicators of SES were more strongly associated with a number of health and well-being outcomes than objective indicators (Rivenbark et al., 2020).

Second, we found important differences between the models fitted separately on male and female data. Overall, the model fit was better on the female data. This was notably caused by the fact that the number of children was significantly associated with the reproduction-maintenance trade-off only in the female model, hence making the factorial structure of this latent variable more robust than in the male model. One plausible explanation for this difference is the fact that pregnancy itself is a reproductive trait that conveys direct maintenance costs for women (Jasienska et al., 2017). Indeed, the number of pregnancies (parity) has been found to be associated with markers of accelerated aging in women (Ryan et al., 2018). In addition, parity is robustly associated with increased risk of cardiovascular disease (Lawlor et al., 2003; Ness et al., 1993) and diabetes (Hinkula et al., 2006).

Third, visualizing the relationships between the latent constructs of the EVS and ESS male and female models reveals an interesting and unexpected pattern (see Supplementary Figures S1 and S2): whereas there is an approximately linear decrease in the Reproduction-maintenance trade-off and Early life adversity latent scores with increasing Perceived control and Time orientation scores, this trend seems to break somewhat at more extreme values of the latter variables, especially for women. In order to quantify this pattern, we ran exploratory series (8 series: 2 gender $\times 2$ associations $\times 2$ surveys) of 3 mixed-effects models (using a maximum likelihood estimator) that we compared by means of likelihood ratio tests (using the lme function of the nlme $\mathrm{R}$ package, Pinheiro et al., 2021). While all 3 models of a series included random subject intercepts, the $1^{\text {st }}$ one modelled the association of Perceived control and Time orientation with Early life adversity or with Reproductionmaintenance trade-off as a linear function, the $2^{\text {nd }}$ one and the $3^{\text {rd }}$ one modelled it as degree 2 and degree 3 polynomials, respectively. These post-hoc analyses first revealed that, for both males and females, the model that best fitted the association of Perceived control with Early life adversity as well as with Reproduction-maintenance trade-off was a degree 3 polynomial (cubic) model that included linear, quadratic and cubic terms as fixed-effects (see Supplementary Tables S4 and S5). Similarly, for both males and females, the model that best fitted the association of Time orientation with Early life adversity as well as with Reproduction-maintenance trade-off was a degree 2 polynomial (quadratic) model that included both a linear and a quadratic term as fixed effects (see Supplementary Tables S6 and S7). These nonlinear patterns could result from some methodological artefacts, but they could also reveal a meaningful effect so far unaccounted for. Based on recent evidence of increased competences in individuals who have experienced more adversity (Frankenhuis \& Nettle, 2020; Ellis et al, 2020), an intriguing possibility is that the nonlinear patterns we characterized above are, in these individuals, the outcomes of an increased sense of confidence in their own abilities. More specifically, some individuals who have experienced significant adversity might develop better abilities in certain cognitive and behavioural domains (e.g., threat detection, task set shifting). The increased sense of control and present orientation observed at the highest scores of early life adversity and reproduction-maintenance trade-off could then be the result of (accurate) perception of these increased abilities: individuals feel (and may in fact be) well equipped to deal with challenges found in adverse conditions and would therefore experience greater control over events that affect their lives. Alternatively, these observations could be simple methodological artefacts. For example, if respondents were unable to answer the perceived control or time orientation item questionnaire accurately (either because they did not understand the wording or because they were under high cognitive load and could not deliberate thoroughly), they might have responded with the maximum score. In this case, respondents with a perceived control score of 10 (or a time orientation of 0 ) would reflect both people who 
deliberately and accurately answered in this way and those who got it wrong, and whose actual scores would be distributed throughout the range of the variable.

Finally, our study also present important limitations. Due to the correlational nature of the EVS and ESS datasets, it is impossible to draw any conclusions about causality from our results. Individuals with a generally lower perceived control may be more likely to experience economic and social adversity, and people who favour reproductive goals over health goals may be more likely to have less control over their lives, rather than the other way around. However, this interpretation is unlikely to hold for several reasons. First, data were collected on adversity experienced during childhood, rather than currently. It is unlikely that the current perceived control retrospectively affects past experience, even though in the EVS and the ESS surveys, selfreported past experience may be corrupted by some sources of noise, such as social desirability effects or distorted memories. Second, other studies with longitudinal designs have also provided support for time-dependent associations between early life adversity and the development of reproductive physiology (Amir et al., 2016). An additional caveat of our work is related to the fact that the EVS and ESS datasets are by definition restricted to European countries. Cross-cultural variability should not be underestimated when considering supposedly universal phenomena (Henrich et al., 2010). Our results therefore need to be replicated in a more diverse sample which would include non-Western and non-industrialized societies. Note however that previous studies working with more culturally diverse groups of subjects have shown that environmental adversity (measured directly or indirectly) impacts cognition (e.g., intertemporal choice) and behaviour (social and academic behaviours) in relatively similar ways across these groups (Bulley \& Pepper, 2017; Chang et al., 2019).

In conclusion, our study contributes to elucidating the complex effects of early life adversity on human psychology. Theory suggests that perceived control and time orientation may be two important psychological traits that mediate the effects of adversity in health and reproduction. Individuals may be less willing to invest in long-term strategies such as health maintenance when they believe that their lives, and the events that affect them, are not under their own control. Instead, they might invest in activities that offer more immediate fitness benefits, such as reproduction. We tested this hypothesis using a public survey dataset and cross-validated structural equation models and found some support for it. Nevertheless, the small effect size indicates that much work remains to be done to fully characterize the relevant constructs and trade-offs.

\section{Data availability}

The EVS and WVS data used in the present study are respectively available at http://www.worldvaluessurvey.org/WVSDocumentationWVL.jsp and at https://dbk.gesis.org/dbksearch/sdesc2.asp?no $=4804 \& d b=e \& d o i=10.4232 / 1.12253$. The EVS and the WVS data used in the present study, the R codes developed to extract and pre-process the data, to perform multiple imputations, to fit and cross-validate the models on the imputed data files, as well as files containing all the results, are available at https://osf.io/dh4jq/.

\section{References}

Amir, D., Jordan, M. R., \& Bribiescas, R. G. (2016). A Longitudinal Assessment of Associations between Adolescent Environment, Adversity Perception, and Economic Status on Fertility and Age of Menarche. PLOS ONE, 11(6), e0155883.

https://doi.org/10.1371/journal.pone.0155883 
Arlot, S., \& Celisse, A. (2010). A survey of cross-validation procedures for model selection. Statistics Surveys, 4, 40-79. https://doi.org/10.1214/09-SS054

Bandura, A. (1977). Self-efficacy: Toward a unifying theory of behavioral change. Psychological Review, 84, 191-215. https://doi.org/10.1037/0033-295X.84.2.191

Barger, S. D., \& Muldoon, M. F. (2006). Hypertension labelling was associated with poorer selfrated health in the Third US National Health and Nutrition Examination Survey. Journal of Human Hypertension, 20(2), 117-123. https://doi.org/10.1038/sj.jhh.1001950

Bar-Sadeh, B., Rudnizky, S., Pnueli, L., Bentley, G. R., Stöger, R., Kaplan, A., \& Melamed, P. (2020). Unravelling the role of epigenetics in reproductive adaptations to early-life environment. Nature Reviews Endocrinology, 16(9), 519-533. https://doi.org/10.1038/s41574-020-0370-8

Benyamini, Y., \& Idler, E. L. (1999). Community Studies Reporting Association between SelfRated Health and Mortality: Additional Studies, 1995 to 1998. Research on Aging, 21(3), 392-401. https://doi.org/10.1177/0164027599213002

Breckler, S. J. (1990). Applications of Covariance Structure Modeling in Psychology: Cause for Concern? Psychological Bulletin, 107(2), 260-273.

Brumbach, B. H., Figueredo, A. J., \& Ellis, B. J. (2009). Effects of Harsh and Unpredictable Environments in Adolescence on Development of Life History Strategies: A Longitudinal Test of an Evolutionary Model. Human Nature, 20(1), 25-51. https://doi.org/10.1007/s12110-009-9059-3

Bulley, A., \& Pepper, G. V. (2017). Cross-country relationships between life expectancy, intertemporal choice and age at first birth. Evolution and Human Behavior, 38(5), 652-658. https://doi.org/10.1016/j.evolhumbehav.2017.05.002

Chang, L., Lu, H. J., Lansford, J. E., Skinner, A. T., Bornstein, M. H., Steinberg, L., Dodge, K. A., Chen, B. B., Tian, Q., Bacchini, D., Deater-Deckard, K., Pastorelli, C., Alampay, L. P., Sorbring, E., Al-Hassan, S. M., Oburu, P., Malone, P. S., Di Giunta, L., Tirado, L. M. U., \& Tapanya, S. (2019). Environmental harshness and unpredictability, life history, and social and academic behavior of adolescents in nine countries. Developmental Psychology, 55(4), 890-903. https://doi.org/10.1037/dev0000655

Culpin, I., Stapinski, L., Miles, Ö.B., Araya, R., Joinson, C. (2015). Exposure to socioeconomic adversity in early life and risk of depression at 18 years: the mediating role of locus of control. Journal of Affective Disorders, 183, 269-278. http://dx.doi.org/10.1016/j.jad.2015.05.030

Del Giudice, M., Gangestad, S. W., \& Kaplan, H. S. (2015). Life History Theory and Evolutionary Psychology. In D. M. Buss (Ed.), The Handbook of Evolutionary Psychology: Vol. 1: Foundations (2nd ed., pp. 88-114). Wiley.

Di Pentima, L., Toni, A., Schneider, B.H., Tomás, J., Amparo, O., Attili, G. (2019). Locus of control as a mediator of the association between attachment and children's mental health. The Journal of Genetic Psychology, 180 (6), 251-265. https://doi.org/10.1080/00221325.2019.1652557

Ellis, B. J., \& Del Giudice, M. (2019). Developmental Adaptation to Stress: An Evolutionary Perspective. Annual Review of Psychology, 70(1), 111-139. https://doi.org/10.1146/annurevpsych-122216-011732

Ellis, B. J., Abrams, L. S., Masten, A., Sternberg, R. J., Tottenham, N., \& Frankenhuis, W. E. (2020). Hidden talents in harsh environments. Development and Psychopathology, 1, 19 https://doi.org/10.1017/S0954579420000887 
Frankenhuis, W. E., \& Nettle, D. (2020). The Strengths of People in Poverty. Current Directions in Psychological Science, 29(1), 16-21. https://doi.org/10.1177/0963721419881154

Goldberg, P., Guéguen, A., Schmaus, A., Nakache, J.-P., \& Goldberg, M. (2001). Longitudinal study of associations between perceived health status and self reported diseases in the French Gazel cohort. Journal of Epidemiology \& Community Health, 55(4), 233-238. https://doi.org/10.1136/jech.55.4.233

Grace, J. B., \& Bollen, K. A. (2008). Representing general theoretical concepts in structural equation models: The role of composite variables. Environmental and Ecological Statistics, 15(2), 191-213. https://doi.org/10.1007/s10651-007-0047-7

Haring, R., Feng, Y.-S., Moock, J., Völzke, H., Dörr, M., Nauck, M., Wallaschofski, H., \& Kohlmann, T. (2011). Self-perceived quality of life predicts mortality risk better than a multi-biomarker panel, but the combination of both does best. BMC Medical Research Methodology, 11(1), 103. https://doi.org/10.1186/1471-2288-11-103

Henrich, J., Heine, S. J., \& Norenzayan, A. (2010). The weirdest people in the world? Behavioral and Brain Sciences, 33(2-3), 61-83. https://doi.org/10.1017/S0140525X0999152X

Hill, K., \& Kaplan, H. (1999). Life History Traits in Humans: Theory and Empirical Studies. Annual Review of Anthropology, 28(1), 397-430. https://doi.org/10.1146/annurev.anthro.28.1.397

Hinkula, M., Kauppila, A., Näyhä, S., \& Pukkala, E. (2006). Cause-specific Mortality of Grand Multiparous Women in Finland. American Journal of Epidemiology, 163(4), 367-373. https://doi.org/10.1093/aje/kwj048

Hu, L., \& Bentler, P. M. (1999). Cutoff criteria for fit indexes in covariance structure analysis: Conventional criteria versus new alternatives. Structural Equation Modeling, 6(1), 1-55. https://doi.org/10.1080/10705519909540118

Hughes, K., Bellis, M. A., Hardcastle, K. A., Sethi, D., Butchart, A., Mikton, C., Jones, L., \& Dunne, M. P. (2017). The effect of multiple adverse childhood experiences on health: A systematic review and meta-analysis. The Lancet Public Health, 2(8), e356-e366. https://doi.org/10.1016/S2468-2667(17)30118-4

Idler, E. L., \& Benyamini, Y. (1997). Self-Rated Health and Mortality: A Review of Twenty-Seven Community Studies. Journal of Health and Social Behavior, 38(1), 21. https://doi.org/10.2307/2955359

Jasienska, G., Bribiescas, R. G., Furberg, A.-S., Helle, S., \& Núñez-de la Mora, A. (2017). Human reproduction and health: An evolutionary perspective. The Lancet, 390(10093), 510-520. https://doi.org/10.1016/S0140-6736(17)30573-1

Johnson, D. R., \& Creech, J. C. (1983). Ordinal Measures in Multiple Indicator Models: A Simulation Study of Categorization Error. American Sociological Review, 48(3), 398. https://doi.org/10.2307/2095231

Jorgensen, T. D., Pornprasertmanit, S., Schoemann, A. M., \& Rosseel, Y. (2020). SemTools: Useful tools for structural equation modeling. R package version 0.5-3. https://CRAN.Rproject.org $/$ package $=$ semTools

Jylhä, M., Volpato, S., \& Guralnik, J. M. (2006). Self-rated health showed a graded association with frequently used biomarkers in a large population sample. Journal of Clinical Epidemiology, 59(5), 465-471. https://doi.org/10.1016/j.jclinepi.2005.12.004

Kline, R. B. (2015). Principles and Practice of Structural Equation Modeling (4th ed.). Guilford Press. 
Kraus, M. W., Piff, P. K., Mendoza-Denton, R., Rheinschmidt, M. L., \& Keltner, D. (2012). Social class, solipsism, and contextualism: How the rich are different from the poor. Psychological Review, 119(3), 546-572. https://doi.org/10.1037/a0028756

Kuzawa, C. W., Chugani, H. T., Grossman, L. I., Lipovich, L., Muzik, O., Hof, P. R., Wildman, D. E., Sherwood, C. C., Leonard, W. R., \& Lange, N. (2014). Metabolic costs and evolutionary implications of human brain development. Proceedings of the National Academy of Sciences, 111(36), 13010-13015. https://doi.org/10.1073/pnas.1323099111

Lawlor, D. A., Emberson, J. R., Ebrahim, S., Whincup, P. H., Wannamethee, S. G., Walker, M., \& Smith, G. D. (2003). Is the Association Between Parity and Coronary Heart Disease Due to Biological Effects of Pregnancy or Adverse Lifestyle Risk Factors Associated With Child-Rearing?: Findings From the British Women's Heart and Health Study and the British Regional Heart Study. Circulation, 107(9), 1260-1264. https://doi.org/10.1161/01.CIR.0000053441.43495.1A

Lefcourt, H. (1976). Locus of control: Current trends in theory and re-search. New York: Wiley.

Legleye, S., Janssen, E., Beck, F., Chau, N., \& Khlat, M. (2011). Social gradient in initiation and transition to daily use of tobacco and cannabis during adolescence: A retrospective cohort study: Tobacco and cannabis use during adolescence. Addiction, 106(8), 1520-1531. https://doi.org/10.1111/j.1360-0443.2011.03447.x

Lettinga, N., Mell, H., Algan, Y., Jacquet, P.O.*, \& Chevallier, C*. (2021). Childhood environmental adversity is not linked to lower levels of cooperative behaviour in economic games. Evolutionary Human Sciences, 3(e29), 1-22. doi:10.1017/ehs.2021.21

Maier, S.F., \& Seligman, M.E. (1976). Learned helpless-ness: Theory and evidence. Journal of Experi-mental Psychology, 105(1), 3-46. https://doi.org/10.1037/0096-3445.105.1.3

McDade, T. W. (2005). Life history, maintenance, and the early origins of immune function. American Journal of Human Biology, 17(1), 81-94. https://doi.org/10.1002/ajhb.20095

McDade, T. W., Georgiev, A. V., \& Kuzawa, C. W. (2016). Trade-offs between acquired and innate immune defenses in humans. Evolution, Medicine, and Public Health, 2016(1), 1-16. https://doi.org/10.1093/emph/eov033

Mell, H., Baumard, N., \& André, J.-B. (2021). Time is money. Waiting costs explain why selection favors steeper time discounting in deprived environments. Evolution and Human Behavior, S1090513821000143. https://doi.org/10.1016/j.evolhumbehav.2021.02.003

Mell, H., Safra, L., Algan, Y., Baumard, N., \& Chevallier, C. (2018). Childhood environmental harshness predicts coordinated health and reproductive strategies: A cross-sectional study of a nationally representative sample from France. Evolution and Human Behavior, 39(1), 18. https://doi.org/10.1016/j.evolhumbehav.2017.08.006

Melotti, R., Heron, J., Hickman, M., Macleod, J., Araya, R., \& Lewis, G. (2011). Adolescent Alcohol and Tobacco Use and Early Socioeconomic Position: The ALSPAC Birth Cohort. PEDIATRICS, 127(4), e948-e955. https://doi.org/10.1542/peds.2009-3450

Miller, G. E., Chen, E., \& Parker, K. J. (2011). Psychological stress in childhood and susceptibility to the chronic diseases of aging: Moving toward a model of behavioral and biological mechanisms. Psychological Bulletin, 137(6), 959-997. https://doi.org/10.1037/a0024768

Nandi, A., Glymour, M. M., \& Subramanian, S. V. (2014). Association Among Socioeconomic Status, Health Behaviors, and All-Cause Mortality in the United States: Epidemiology, 25(2), 170-177. https://doi.org/10.1097/EDE.0000000000000038 
Ness, R. B., Harris, T., Cobb, J., Flegal, K. M., Kelsey, J. L., Balanger, A., Stunkard, A. J., \& D'Agostino, R. B. (1993). Number of pregnancies and the subsequent risk of cardiovascular disease. The New England Journal of Medicine, 328(21), 1528-1533.

Nettle, D. (2010). Dying young and living fast: Variation in life history across English neighborhoods. Behavioral Ecology, 21(2), 387-395.

https://doi.org/10.1093/beheco/arp202

Nettle, D. (2011). Flexibility in reproductive timing in human females: Integrating ultimate and proximate explanations. Philosophical Transactions of the Royal Society B: Biological Sciences, 366(1563), 357-365. https://doi.org/10.1098/rstb.2010.0073

Nettle, D., Coall, D. A., \& Dickins, T. E. (2011). Early-life conditions and age at first pregnancy in British women. Proceedings of the Royal Society B: Biological Sciences, 278(1712), 1721-1727. https://doi.org/10.1098/rspb.2010.1726

Nettle, D., \& Frankenhuis, W. E. (2019). The evolution of life-history theory: A bibliometric analysis of an interdisciplinary research area. Proceedings of the Royal Society B: Biological Sciences, 286(1899), 20190040. https://doi.org/10.1098/rspb.2019.0040

Norman, G. (2010). Likert scales, levels of measurement and the "laws" of statistics. Advances in Health Sciences Education, 15(5), 625-632. https://doi.org/10.1007/s10459-010-9222-y

Oberski, D. (2014). lavaan.survey: An R Package for Complex Survey Analysis of Structural Equation Models. Journal of Statistical Software, 57(1). https://doi.org/10.18637/jss.v057.i01

Pepper, G. V., \& Nettle, D. (2014). Perceived Extrinsic Mortality Risk and Reported Effort in Looking after Health: Testing a Behavioral Ecological Prediction. Human Nature, 25(3), 378-392. https://doi.org/10.1007/s12110-014-9204-5

Pepper, G. V., \& Nettle, D. (2017). The behavioural constellation of deprivation: Causes and consequences. Behavioral and Brain Sciences, 40, e314. https://doi.org/10.1017/S0140525X1600234X

Piketty, T., \& Saez, E. (2014). Inequality in the long run. Science, 344(6186), 838-843. https://doi.org/10.1126/science.1251936

Pinheiro J, Bates D, DebRoy S, Sarkar D, R Core Team (2021). nlme: Linear and Nonlinear Mixed Effects Models. R package version 3.1-152, https://CRAN.Rproject.org $/$ package $=$ nlme

Preacher, K. J. (2006). Quantifying Parsimony in Structural Equation Modeling. Multivariate Behavioral Research, 41(3), 227-259. https://doi.org/10.1207/s15327906mbr4103_1

Rivenbark, J., Arseneault, L., Caspi, A., Danese, A., Fisher, H. L., Moffitt, T. E., Rasmussen, L. J. H., Russell, M. A., \& Odgers, C. L. (2020). Adolescents' perceptions of family social status correlate with health and life chances: A twin difference longitudinal cohort study. Proceedings of the National Academy of Sciences, 201820845. https://doi.org/10.1073/pnas.1820845116

Roberts, S., \& Pashler, H. (2000). How Persuasive Is a Good Fit? A Comment on Theory Testing. Psychological Review, 107(2), 358-367.

Rosseel, Y. (2012). lavaan: An R Package for Structural Equation Modeling. Journal of Statistical Software, 48(2). https://doi.org/10.18637/jss.v048.i02

Rotter, J.B. (1966). Generalized expectancies for internal versus external control of reinforcement. Psychological Monographs: General and Applied, 80(1), 1-28. doi:10.1037/ b0092976 
Ryan, C. P., Hayes, M. G., Lee, N. R., McDade, T. W., Jones, M. J., Kobor, M. S., Kuzawa, C. W., \& Eisenberg, D. T. A. (2018). Reproduction predicts shorter telomeres and epigenetic age acceleration among young adult women. Scientific Reports, 8(1), 11100. https://doi.org/10.1038/s41598-018-29486-4

Satorra, A., \& Bentler, P. M. (2001). A scaled difference chi-square test statistic for moment structure analysis. Psychometrika, 66(4), 507-514.

Sear, R. (2020). Do human 'life history strategies' exist? Evolution and Human Behavior, 41(6), 513526. https://doi.org/10.1016/j.evolhumbehav.2020.09.004

Shapiro Jr., D.H., Blinder, B.J., Hagman, J., Pituck, S. (1993). A psychological “sense-of-control" profile of patients with anorexia nervosa and bulimia nervosa. Psychological Reports, 73, 531-541. https://doi.org/10.2466/pr0.1993.73.2.531

Smith, K. E., \& Pollak, S. D. (2021). Rethinking Concepts and Categories for Understanding the Neurodevelopmental Effects of Childhood Adversity. Perspectives on Psychological Science, 16(1), 67-93. https://doi.org/10.1177/1745691620920725

Stevens, J. R., \& Stephens, D. W. (2010). The adaptive nature of impulsivity. In G. J. Madden \& W. K. Bickel (Eds.), Impulsivity: The behavioral and neurological science of discounting. (pp. 361387). American Psychological Association. https://doi.org/10.1037/12069-013

Sullivan, G. M., \& Artino Jr, A. R. (2013). Analyzing and interpreting data from Likert-type scales. Journal of graduate medical education, 5(4), 541. https:// doi.org/10.4300/JGME-5-4-18

van Buuren, S., \& Groothuis-Oudshoorn, K. (2011). mice: Multivariate Imputation by Chained Equations in R. Journal of Statistical Software, 45(3). https://doi.org/10.18637/jss.v045.i03

Zimbardo, P.G., Boyd, J.N. (1999). Putting time in perspective: a valid, reliable individualdifferences metric. Journal of personality and social psychology, 77(6), 1271-1288.

Zucman, G. (2019). Global Wealth Inequality. Annual Review of Economics, 11, 109-138.

Zumbo, B. D., \& Zimmerman, D. W. (1993). Is the selection of statistical methods governed by level of measurement? Canadian Psychology, 34(4), 390-400. https://doi.org/10.1037/h0078865 
Do perceived control and time orientation mediate the effect of early life adversity on reproductive behaviour and health status? Insights from the European Value Study and the European Social Survey.

Bence Csaba Farkas ${ }^{1}$, Valérian Chambon², Pierre O. Jacquet ${ }^{1}$

${ }^{1} \mathrm{LNC}^{2}$, Département d'études cognitives, École normale supérieure, INSERM, PSL Research University, 75005 Paris, France.

${ }^{2}$ Institut Jean Nicod, Département d'études cognitives, ENS, EHESS, CNRS, PSL Research University, 75005 Paris, France.

\section{Supplementary Information}

1. Supplementary Table S1. Descriptive statistics of the variables of the EVS and ESS datasets.

2. Supplementary Table S2. Description of indicators used in the EVS and ESS models.

3. Supplementary Table S3. Observed correlation matrices of the variables of the EVS and ESS datasets.

4. Supplementary Figure S1. Visualizing the relationships between the EVS modeled variables.

5. Supplementary Figure S2. Visualizing the relationships between the ESS modeled variables.

6. Supplementary Table S4. Model comparisons for the EVS mixed models corresponding.

7. Supplementary Table S5. Fixed effects for the EVS mixed models.

8. Supplementary Table S6. Model comparisons for the ESS mixed models corresponding.

9. Supplementary Table S7. effects for the ESS mixed models. 


\begin{tabular}{lllllllllll}
\hline EVS variables & $\mathbf{N}$ & Mean & SD & Median & Min & Max & Range & Skew & Kurtosis SE \\
\hline $\begin{array}{l}\text { Economic capital } \\
\text { deprivation }\end{array}$ & 43084 & 4.57 & 3.60 & 4.98 & 0 & 10 & 10 & 0.12 & -1.33 & 0.02 \\
$\begin{array}{l}\text { Human capital deprivation } \\
\text { Experienced childhood }\end{array}$ & 43084 & 6.22 & 2.28 & 6.35 & 0 & 10 & 10 & -0.32 & -0.50 & 0.01 \\
mortality & 43084 & 0.33 & 1.28 & 0 & 0 & 10 & 10 & 3.77 & 13.62 & 0.01 \\
Health & 43084 & 2.41 & 0.96 & 2 & 1 & 5 & 4 & 0.38 & -0.22 & 0.01 \\
Age at 1st reproduction & 43084 & 25.26 & 5.25 & 24 & 12 & 89 & 77 & 1.31 & 5.50 & 0.03 \\
Number of children & 43084 & 2.22 & 1.16 & 2 & 1 & 15 & 14 & 2.10 & 9.12 & 0.01 \\
Perceived control & 43084 & 6.71 & 2.32 & 7 & 1 & 10 & 9 & -0.51 & -0.34 & 0.01 \\
Household income & 43084 & 2.05 & 0.76 & 2 & 1 & 3 & 2 & -0.10 & -1.31 & $<0.01$ \\
Age & 43084 & 52.06 & 15.25 & 51 & 16 & 108 & 92 & 0.19 & -0.71 & 0.07 \\
\hline \hline ESS variables & $\mathbf{N}$ & $\mathbf{M e a n}$ & $\mathbf{S D}$ & $\mathbf{M e d i a n}$ & $\mathbf{M i n}$ & $\mathbf{M a x}$ & $\mathbf{R a n g e}$ & Skew & Kurtosis SE \\
\hline $\begin{array}{l}\text { Economic capital } \\
\text { deprivation }\end{array}$ & 31065 & 3.24 & 1.89 & 2.96 & 0 & 10 & 10 & 0.89 & 1.61 & 0.01 \\
Human capital deprivation & 31065 & 7.42 & 2.53 & 8.33 & 0 & 10 & 10 & -0.96 & 0.29 & 0.01 \\
$\begin{array}{l}\text { Experienced childhood } \\
\text { mortality }\end{array}$ & 31065 & 5.02 & 2.98 & 5.25 & 0 & 10 & 10 & -0.18 & -1.15 & 0.02 \\
Health & 31065 & 2.33 & 0.91 & 2 & 1 & 5 & 4 & 0.43 & -0.03 & 0.01 \\
Age at 1st reproduction & 31065 & 26.46 & 5.39 & 26 & 13 & 70 & 57 & 0.82 & 1.18 & 0.03 \\
Number of children & 31065 & 2.13 & 1.04 & 2 & 1 & 10 & 9 & 1.72 & 6.12 & 0.01 \\
Time orientation & 31065 & 5.09 & 3.05 & 5 & 0 & 10 & 10 & 0.05 & -1.07 & 0.02 \\
Household income & 31065 & 5.26 & 2.65 & 5 & 1 & 10 & 9 & 0.11 & -1.06 & 0.02 \\
Age & 31065 & 57.12 & 15.28 & 58 & 17 & 90 & 73 & -0.04 & -0.80 & 0.09 \\
\hline
\end{tabular}

Supplementary Table S1. Descriptive statistics of the variables in the EVS and ESS datasets. Descriptive statistics are computed from the full EVS and ESS samples, i.e. after multiple imputations but before their split into male and female datasets and training and test datasets for cross-validation. These are therefore averages over 20 imputed datasets. 


\begin{tabular}{|c|c|c|c|c|c|c|}
\hline EVS Variable name & $\begin{array}{l}\text { Variable } \\
\text { status }\end{array}$ & Indicator name & Original EVS item & EVS code & Range & $\begin{array}{l}\% \text { missing } \\
\text { data }\end{array}$ \\
\hline \multirow{11}{*}{ Early life adversity } & \multirow{11}{*}{ Composite } & \multirow{2}{*}{$\begin{array}{l}\text { Economic capital } \\
\text { deprivation }\end{array}$} & $\begin{array}{l}\text { Parent(s) had problems } \\
\text { making ends meet }\end{array}$ & v014 & 1 to 4 & 2.54 \\
\hline & & & $\begin{array}{l}\text { Parent(s) had problems } \\
\text { replacing broken things }\end{array}$ & v018 & 1 to 4 & 7.99 \\
\hline & & \multirow{7}{*}{$\begin{array}{l}\text { Human capital } \\
\text { deprivation }\end{array}$} & $\begin{array}{l}\text { Highest educational level } \\
\text { attained father/mother ( } 8 \\
\text { categories) }\end{array}$ & $\mathrm{v} 004 \mathrm{e}$ & 1 to $8 \mathrm{R}$ & 5.95 \\
\hline & & & $\begin{array}{l}\text { Mother liked to read } \\
\text { books }\end{array}$ & v011 & 1 to 4 & 4.59 \\
\hline & & & Father liked to read books & v015 & 1 to 4 & 11.48 \\
\hline & & & $\begin{array}{l}\text { Discussed politics with } \\
\text { mother }\end{array}$ & v012 & 1 to 4 & 3.35 \\
\hline & & & $\begin{array}{l}\text { Discussed politics with } \\
\text { father }\end{array}$ & v016 & 1 to 4 & 10.66 \\
\hline & & & $\begin{array}{l}\text { Mother liked to follow the } \\
\text { news }\end{array}$ & v013 & 1 to 4 & 4.78 \\
\hline & & & $\begin{array}{l}\text { Father liked to follow the } \\
\text { news }\end{array}$ & v017 & 1 to 4 & 11.28 \\
\hline & & \multirow{2}{*}{$\begin{array}{l}\text { Experienced } \\
\text { childhood mortality }\end{array}$} & $\begin{array}{l}\text { Experienced: death of } \\
\text { father }\end{array}$ & u005a & 1 to 2 & 0.00 \\
\hline & & & $\begin{array}{l}\text { Experienced: death of } \\
\text { mother }\end{array}$ & u006a & 1 to 2 & 0.00 \\
\hline \multirow{3}{*}{$\begin{array}{l}\text { Reproduction- } \\
\text { maintenance trade-off }\end{array}$} & \multirow{3}{*}{ Latent } & Health & State of health (subjective) & $\mathrm{a} 009$ & 1 to 5 & 0.25 \\
\hline & & $\begin{array}{l}\text { Age at } 1 \mathrm{st} \\
\text { reproduction }\end{array}$ & $\begin{array}{l}\text { Year in which firstborn } \\
\text { child was born }\end{array}$ & x011_02 & - & 0.00 \\
\hline & & Number of children & $\begin{array}{l}\text { How many children have } \\
\text { you ever had }\end{array}$ & $\mathrm{x} 011$ & - & 0.00 \\
\hline Perceived control & $\begin{array}{l}\text { Single } \\
\text { indicator }\end{array}$ & Perceived control & $\begin{array}{l}\text { How much freedom of } \\
\text { choice and control }\end{array}$ & a173 & 1 to 10 & 2.29 \\
\hline Household income & Covariate & Household income & Income level & $\mathrm{x} 047 \mathrm{r}$ & 1 to 3 & 15.29 \\
\hline Age & Covariate & Age & Age & $\mathrm{x} 003$ & - & 0.00 \\
\hline ESS Variable name & $\begin{array}{l}\text { Variable } \\
\text { status }\end{array}$ & Indicator name & Original ESS item & ESS code & Range & $\begin{array}{l}\% \text { missing } \\
\text { data }\end{array}$ \\
\hline \multirow{5}{*}{ Early life adversity } & \multirow{5}{*}{ Composite } & \multirow{3}{*}{$\begin{array}{l}\text { Economic capital } \\
\text { deprivation }\end{array}$} & $\begin{array}{l}\text { Father's employment } \\
\text { status when respondent } 14\end{array}$ & emprf14 & 1 to 4 & 4.04 \\
\hline & & & $\begin{array}{l}\text { Mother's employment } \\
\text { status when respondent } 14\end{array}$ & emprm14 & 1 to 4 & 2.58 \\
\hline & & & $\begin{array}{l}\text { Father's occupation when } \\
\text { respondent } 14\end{array}$ & occf14b & 1 to 9 & 16.38 \\
\hline & & \multirow{2}{*}{$\begin{array}{l}\text { Human capital } \\
\text { deprivation }\end{array}$} & $\begin{array}{l}\text { Father's highest level of } \\
\text { education, ES - ISCED }\end{array}$ & eiscedf & 1 to $7 \mathrm{R}$ & 9.43 \\
\hline & & & $\begin{array}{l}\text { Mother's highest level of } \\
\text { education, ES - ISCED }\end{array}$ & eiscedm & 1 to $7 \mathrm{R}$ & 6.27 \\
\hline \multirow{3}{*}{$\begin{array}{l}\text { Reproduction- } \\
\text { maintenance trade-off }\end{array}$} & \multirow{3}{*}{ Latent } & Health & Subjective general health & health & 1 to 5 & 0.48 \\
\hline & & $\begin{array}{l}\text { Age at } 1 \mathrm{st} \\
\text { reproduction }\end{array}$ & Year (first) child was born & fcldbrn & - & 2.13 \\
\hline & & Number of children & $\begin{array}{l}\text { Number of children ever } \\
\text { given birth to/ fathered }\end{array}$ & nbthcld & - & 0.68 \\
\hline Time orientation & $\begin{array}{l}\text { Single } \\
\text { indicator }\end{array}$ & Time orientation & $\begin{array}{l}\text { Plan for future or take } \\
\text { each day as it comes }\end{array}$ & plnftr & 0 to 10 & 0.83 \\
\hline Household income & Covariate & Household income & $\begin{array}{l}\text { Household's total net } \\
\text { income, all sources }\end{array}$ & hinctnta & 1 to 10 & 17.60 \\
\hline Age & Covariate & Age & $\begin{array}{l}\text { Age of respondent, } \\
\text { calculated }\end{array}$ & agea & - & 0.78 \\
\hline
\end{tabular}

Supplementary Table S2. Description of the indicators used in the EVS and ESS models. Described are the names of the variables reported in the model; their status in the models; the names of the indicators used in the models; their names as EVS/ESS items; their corresponding EVS/ESS codes; their original score ranges ( $\mathrm{R}$ indicates that the scores have been reversed); and their percentages of missing data. 


\begin{tabular}{|c|c|c|c|c|c|c|c|c|c|c|}
\hline EVS & & 1 & 2 & 3 & 4 & 5 & 6 & 7 & 8 & 9 \\
\hline $\begin{array}{l}\text { Economic capital } \\
\text { deprivation }\end{array}$ & 1 & - & & & & & & & & \\
\hline $\begin{array}{l}\text { Human capital } \\
\text { deprivation }\end{array}$ & 2 & .22 & - & & & & & & & \\
\hline $\begin{array}{l}\text { Experienced } \\
\text { childhood mortality }\end{array}$ & 3 & .10 & .06 & - & & & & & & \\
\hline Health & 4 & .19 & .20 & .07 & - & & & & & \\
\hline $\begin{array}{l}\text { Age at } 1 \text { st } \\
\text { reproduction }\end{array}$ & 5 & -.09 & -.10 & -.02 & -.10 & - & & & & \\
\hline Number of children & 6 & .09 & .14 & .03 & .08 & -.19 & - & & & \\
\hline Perceived control & 7 & -.10 & -.10 & -.01 & -.19 & .03 & .00 & - & & \\
\hline Household income & 8 & .18 & .23 & .06 & .26 & -.11 & .11 & -.11 & - & \\
\hline Age & 9 & .15 & .18 & .11 & .33 & .11 & .24 & -.05 & .25 & - \\
\hline ESS & & 1 & 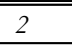 & 3 & 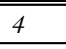 & $\overline{5}$ & 6 & 7 & 8 & 9 \\
\hline $\begin{array}{l}\text { Economic capital } \\
\text { deprivation }\end{array}$ & 1 & - & & & & & & & & \\
\hline $\begin{array}{l}\text { Human capital } \\
\text { deprivation }\end{array}$ & 2 & .52 & - & & & & & & & \\
\hline $\begin{array}{l}\text { Experienced } \\
\text { childhood mortality }\end{array}$ & 3 & -.07 & .05 & - & & & & & & \\
\hline Health & 4 & -.24 & .21 & .08 & - & & & & & \\
\hline $\begin{array}{l}\text { Age at } 1 \text { st } \\
\text { reproduction }\end{array}$ & 5 & -.13 & -.16 & -.07 & -.17 & - & & & & \\
\hline Number of children & 6 & .12 & .14 & .04 & .06 & -.25 & - & & & \\
\hline Time orientation & 7 & .08 & .16 & .05 & .20 & -.10 & .10 & - & & \\
\hline Household income & 8 & -.24 & -.33 & -.09 & -.31 & .23 & -.09 & -.24 & - & \\
\hline Age & 9 & .20 & .35 & .08 & .37 & -.10 & .20 & .23 & -.31 & - \\
\hline
\end{tabular}

Supplementary Table S3. Observed correlation matrices of the variables in the EVS and ESS datasets. Correlations are calculated from the full EVS and ESS samples, i.e., after multiple imputations but before their split into male and female datasets and training and test datasets for cross-validation. These are therefore averages over 20 imputed datasets. 

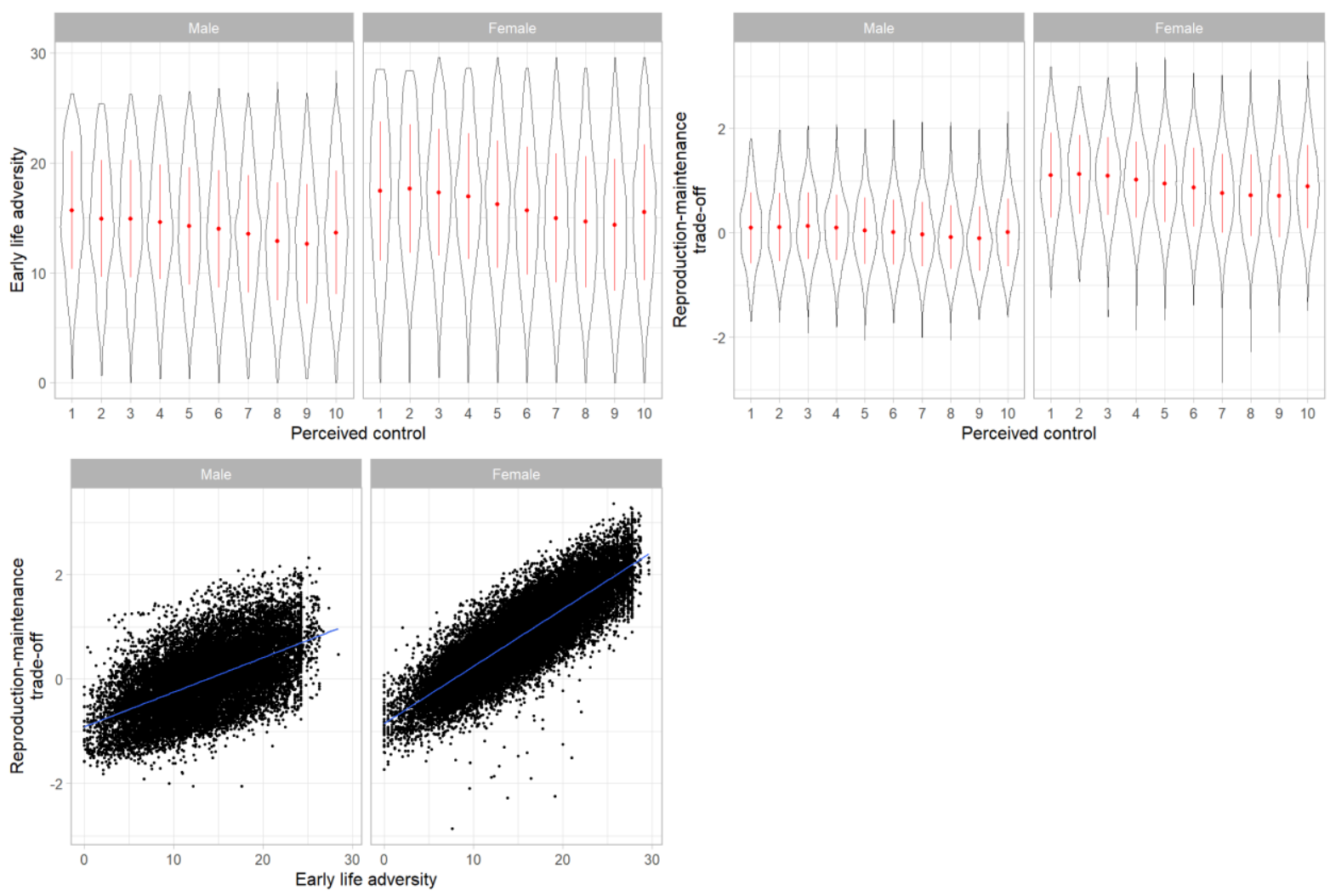

Supplementary Figure S1. Visualizing the relationships between the EVS modelled variables. Violin plots indicate the distributions of data, along with mean and 1 SD with a red colour. Scatter plots represent the individual data points fitted a linear model $(\mathrm{lm})$. 

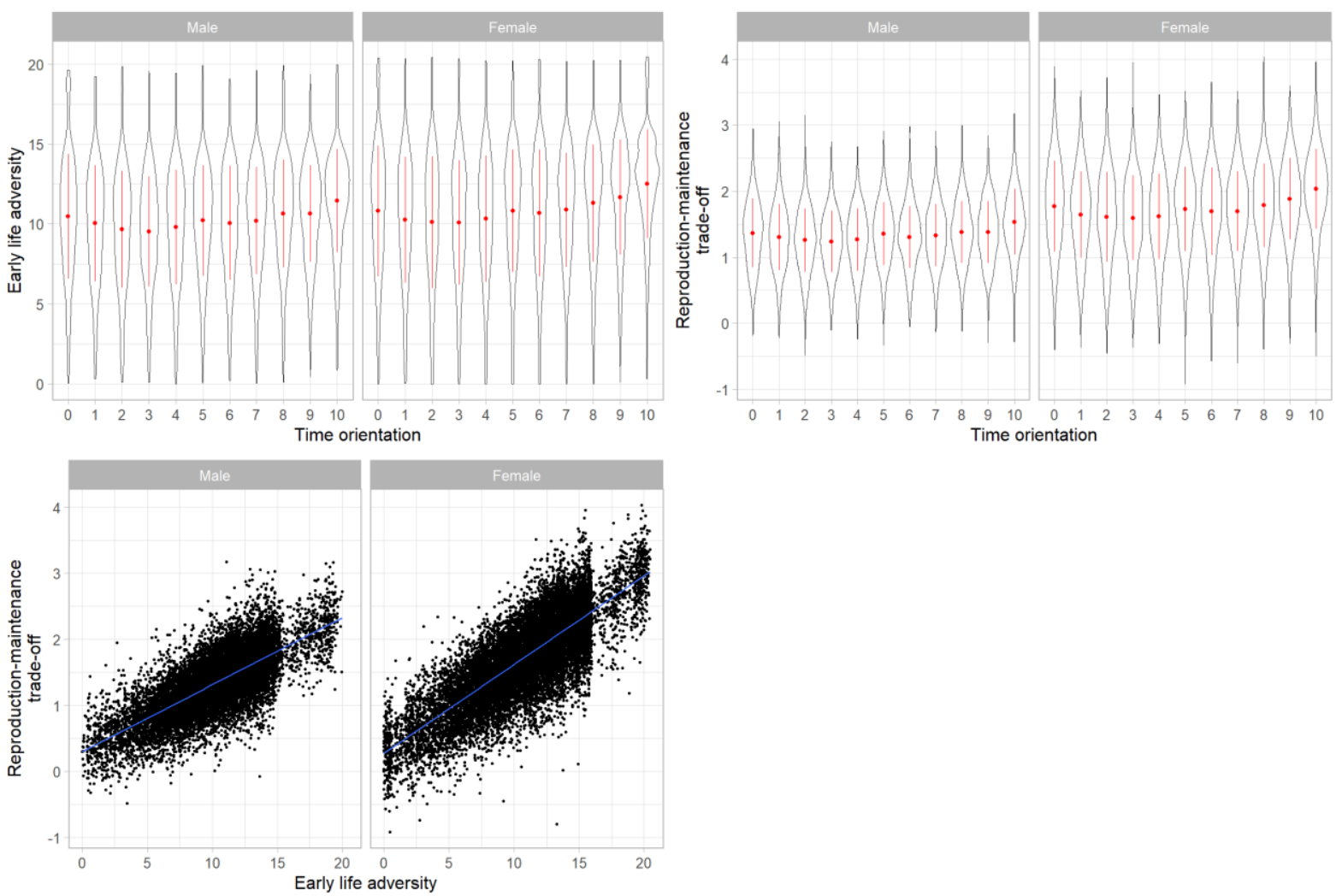

Supplementary Figure S2. Visualizing the relationships between the ESS modelled variables. Violin plots indicate the distributions of data, along with mean and 1 SD with a red colour. Scatter plots represent the individual data points fitted with a linear model $(\mathrm{lm})$. 


\begin{tabular}{|c|c|c|c|c|c|c|}
\hline \multicolumn{7}{|c|}{ Model comparisons } \\
\hline \multicolumn{7}{|c|}{ Association of Perceived control and Early life adversity } \\
\hline \multicolumn{7}{|c|}{ EVS Male } \\
\hline Models & df & AIC & BIC & logLik & $x^{2}$ & $\mathrm{p}$ \\
\hline Linear & 4 & 110258.1 & 110289.2 & -55125.06 & & \\
\hline Quadratic & 5 & 110228.4 & 110267.3 & -55109.19 & 31.73 & $<.001$ \\
\hline Cubic & 6 & 110185.9 & 110232.6 & -55086.96 & 44.46 & $<.001$ \\
\hline \multicolumn{7}{|c|}{ EVS Female } \\
\hline Models & df & AIC & BIC & logLik & $x^{2}$ & $\mathrm{p}$ \\
\hline Linear & 4 & 162371.2 & 162403.8 & -81181.60 & & \\
\hline Quadratic & 5 & 162311.0 & 162351.7 & -81150.51 & 62.18 & $<.001$ \\
\hline Cubic & 6 & 162189.0 & 162237.8 & -81088.48 & 124.06 & $<.001$ \\
\hline \multicolumn{7}{|c|}{ Association of Perceived control and Reproduction-maintenance trade-of } \\
\hline \multicolumn{7}{|c|}{ EVS Male } \\
\hline Models & df & AIC & BIC & logLik & $x^{2}$ & $\mathrm{p}$ \\
\hline Linear & 4 & 33864.45 & 33895.59 & -16928.23 & & \\
\hline Quadratic & 5 & 33848.78 & 33887.70 & -16919.39 & 17.67 & $<.001$ \\
\hline Cubic & 6 & 33785.23 & 33831.93 & -16886.61 & 65.56 & $<.001$ \\
\hline \multicolumn{7}{|c|}{ EVS Female } \\
\hline Models & $\mathrm{df}$ & AIC & BIC & logLik & $x^{2}$ & $\mathrm{p}$ \\
\hline Linear & 4 & 58695.68 & 58728.24 & -29343.84 & & \\
\hline Quadratic & 5 & 58593.67 & 58634.37 & -29291.84 & 104.01 & $<.001$ \\
\hline Cubic & 6 & 58417.93 & 58466.77 & -29202.97 & 177.74 & $<.001$ \\
\hline
\end{tabular}

Supplementary Table S4. Model comparisons of the exploratory EVS mixed models (Linear, Quadratic, Cubic). All models include random intercepts for each subject. 


\begin{tabular}{|c|c|c|c|c|c|c|}
\hline \multicolumn{7}{|c|}{ Model parameters } \\
\hline \multicolumn{7}{|c|}{ Association of Perceived control and Early life adversity } \\
\hline \multicolumn{7}{|c|}{ EVS Male } \\
\hline Models & Fixed effects & b & SE & df & $\mathbf{t}$ & $\mathrm{p}$ \\
\hline \multirow[t]{2}{*}{ Linear } & Intercept & 15.554 & 0.125 & 17741 & 124.31 & $<.001$ \\
\hline & Perceived control & -0.274 & 0.017 & 17741 & -15.77 & $<.001$ \\
\hline \multirow[t]{3}{*}{ Quadratic } & Intercept & 16.689 & 0.237 & 17740 & 70.41 & $<.001$ \\
\hline & Perceived control & -0.713 & 0.080 & 17740 & -8.94 & $<.001$ \\
\hline & Perceived control $^{2}$ & 0.036 & 0.006 & 17740 & 5.64 & $<.001$ \\
\hline \multirow[t]{4}{*}{ Cubic } & Intercept & 14.736 & 0.376 & 17739 & 39.147 & $<.001$ \\
\hline & Perceived control & 0.781 & 0.238 & 17739 & 3.286 & $=.001$ \\
\hline & Perceived control $^{2}$ & -0.259 & 0.045 & 17739 & -5.803 & $<.001$ \\
\hline & Perceived control $^{3}$ & 0.017 & 0.003 & 17739 & 6.671 & $<.001$ \\
\hline \multicolumn{7}{|c|}{ EVS Female } \\
\hline Models & Fixed effects & b & SE & df & $\mathbf{t}$ & $\mathrm{p}$ \\
\hline \multirow[t]{2}{*}{ Linear } & Intercept & 17.865 & 0.113 & 25339 & 158.523 & $<.001$ \\
\hline & Perceived control & -0.345 & 0.016 & 25339 & -21.543 & $<.001$ \\
\hline \multirow[t]{3}{*}{ Quadratic } & Intercept & 19.306 & 0.215 & 25338 & 90.00 & $<.001$ \\
\hline & Perceived control & -0.905 & 0.073 & 25338 & -12.43 & $<.001$ \\
\hline & Perceived control $^{2}$ & 0.046 & 0.006 & 25338 & 7.89 & $<.001$ \\
\hline \multirow[t]{4}{*}{ Cubic } & Intercept & 16.368 & 0.339 & 25337 & 48.22 & $<.001$ \\
\hline & Perceived control & 1.351 & 0.215 & 25337 & 6.28 & $<.001$ \\
\hline & Perceived control $^{2}$ & -0.403 & 0.041 & 25337 & -9.90 & $<.001$ \\
\hline & Perceived control $^{3}$ & 0.026 & 0.002 & 25337 & 11.15 & $<.001$ \\
\hline \multicolumn{7}{|c|}{ Association of Perceived control and Reproduction-maintenance trade-off } \\
\hline \multicolumn{7}{|c|}{ EVS Male } \\
\hline Models & Fixed effects & b & SE & df & t & $\mathrm{p}$ \\
\hline \multirow[t]{2}{*}{ Linear } & Intercept & 0.143 & 0.015 & 17741 & 9.82 & $<.001$ \\
\hline & Perceived control & -0.022 & 0.002 & 17741 & -10.83 & $<.001$ \\
\hline \multirow[t]{3}{*}{ Quadratic } & Intercept & 0.241 & 0.028 & 17740 & 8.76 & $<.001$ \\
\hline & Perceived control & -0.060 & 0.009 & 17740 & -6.46 & $<.001$ \\
\hline & Perceived control $^{2}$ & 0.003 & 0.001 & 17740 & 4,20 & $<.001$ \\
\hline \multirow[t]{4}{*}{ Cubic } & Intercept & -0.034 & 0,044 & 17739 & -0.78 & $=.433$ \\
\hline & Perceived control & 0,151 & 0,028 & 17739 & 5,47 & $<.001$ \\
\hline & Perceived control $^{2}$ & -0.038 & 0,005 & 17739 & -7.42 & $<.001$ \\
\hline & Perceived control $^{3}$ & 0,002 & $<0.001$ & 17739 & 8.10 & $<.001$ \\
\hline \multicolumn{7}{|c|}{ EVS Female } \\
\hline Models & Fixed effects & b & SE & df & $\mathbf{t}$ & $\mathrm{p}$ \\
\hline \multirow[t]{2}{*}{ Linear } & Intercept & 1.139 & 0.015 & 25339 & 78.18 & $<.001$ \\
\hline & Perceived control & -0.043 & 0.002 & 25339 & -20.60 & $<.001$ \\
\hline \multirow[t]{3}{*}{ Quadratic } & Intercept & 1.380 & 0.028 & 25338 & 49.80 & $<.001$ \\
\hline & Perceived control & -0.136 & 0.009 & 25338 & -14.49 & $<.001$ \\
\hline & Perceived control $^{2}$ & 0.008 & $<0.001$ & 25338 & 10.21 & $<.001$ \\
\hline \multirow[t]{4}{*}{ Cubic } & Intercept & 0.926 & 0.044 & 25337 & 21.14 & $<.001$ \\
\hline & Perceived control & 0.212 & 0.028 & 25337 & 7.66 & $<.001$ \\
\hline & Perceived control $^{2}$ & -0.062 & 0.005 & 25337 & 11.75 & $<.001$ \\
\hline & Perceived control $^{3}$ & 0.004 & $<0.001$ & 25337 & 13.35 & $<.001$ \\
\hline
\end{tabular}

Supplementary Table S5. Fixed effects parameters of the exploratory EVS mixed models (Linear, Quadratic, Cubic). All models include random intercepts for each subject. 


\begin{tabular}{|c|c|c|c|c|c|c|}
\hline \multicolumn{7}{|c|}{ Model comparisons } \\
\hline \multicolumn{7}{|c|}{ Association of Time orientation and Early life adversity } \\
\hline \multicolumn{7}{|c|}{ ESS Male } \\
\hline Models & dff & AIC & BIC & logLik & $x^{2}$ & $\mathrm{p}$ \\
\hline Linear & 4 & 71825.99 & 71856.01 & -35908.99 & & \\
\hline Quadratic & 5 & 71700.06 & 71737.58 & -35845.03 & 127.93 & $<.001$ \\
\hline Cubic & 6 & 71693.58 & 71738.50 & -35840.79 & 8.48 & $=.004$ \\
\hline \multicolumn{7}{|c|}{ ESS Female } \\
\hline Models & df & AIC & BIC & logLik & $x^{2}$ & $\mathrm{p}$ \\
\hline Linear & 4 & 97482.32 & 97513.44 & -48737.16 & & \\
\hline Quadratic & 5 & 97311.72 & 97350.61 & -48650.86 & 172.60663 & $<.001$ \\
\hline Cubic & 6 & 97312.56 & 97359.22 & -48650.28 & 1.16261 & $=.281$ \\
\hline \multicolumn{7}{|c|}{ Association of Time orientation and Reproduction-maintenance trade-off } \\
\hline \multicolumn{7}{|l|}{ ESS Male } \\
\hline Models & dff & AIC & BIC & logLik & $x^{2}$ & $\mathrm{p}$ \\
\hline Linear & 4 & 18627.1 & 18657.12 & -9309.550 & & \\
\hline Quadratic & 5 & 18485.41 & 18522.93 & -9237.703 & 143.7 & $<.001$ \\
\hline Cubic & 6 & 18485.81 & 18530.84 & -9236.907 & 1.59 & $=.207$ \\
\hline \multicolumn{7}{|c|}{ ESS Female } \\
\hline Models & $\mathrm{df}$ & AIC & BIC & $\log \mathrm{Lik}$ & $x^{2}$ & $\mathrm{p}$ \\
\hline Linear & 4 & 34763.92 & 34795.03 & -17377.96 & & \\
\hline Quadratic & 5 & 34473.45 & 34512.34 & -17231.73 & 292.46 & $<.001$ \\
\hline Cubic & 6 & 34475.31 & 34521.98 & -17231.66 & 0.14 & $=.710$ \\
\hline
\end{tabular}

Supplementary Table S6. Model comparisons of the exploratory ESS mixed models (Linear, Quadratic, Cubic). All models include random intercepts for each subject. 


\begin{tabular}{|c|c|c|c|c|c|c|}
\hline \multicolumn{7}{|c|}{ Model parameters } \\
\hline \multicolumn{7}{|c|}{ Association of Time orientation and Early life adversity } \\
\hline \multicolumn{7}{|c|}{ ESS Male } \\
\hline Models & Fixed effects & b & SE & df & $\mathbf{t}$ & $\mathrm{p}$ \\
\hline \multirow[t]{2}{*}{ Linear } & Intercept & 9.596 & 0.058 & 13424 & 165.84 & $<.001$ \\
\hline & Time orientation & 0.126 & 0.010 & 13424 & 12.59 & $<.001$ \\
\hline \multirow[t]{3}{*}{ Quadratic } & Intercept & 10.250 & 0.081 & 13423 & 125.77 & $<.001$ \\
\hline & Time orientation & -0.269 & 0.036 & 13423 & -7.41 & $<.001$ \\
\hline & Time orientation ${ }^{2}$ & 0.039 & 0.003 & 13423 & 11.34 & $<.001$ \\
\hline \multirow[t]{4}{*}{ Cubic } & Intercept & 10.400 & 0.095 & 13422 & 108.95 & $<.001$ \\
\hline & Time orientation & -0.478 & 0.080 & 13422 & -5.95 & $<.001$ \\
\hline & Time orientation ${ }^{2}$ & 0.093 & 0.019 & 13422 & 4.91 & $<.001$ \\
\hline & Time orientation $^{3}$ & -0.004 & 0.001 & 13422 & -2.91 & $=.004$ \\
\hline \multicolumn{7}{|c|}{ ESS Female } \\
\hline Models & Fixed effects & b & SE & df & $\mathbf{t}$ & $\mathrm{p}$ \\
\hline \multirow[t]{2}{*}{ Linear } & Intercept & 9.850 & 0.057 & 17637 & 172.31 & $<.001$ \\
\hline & Time orientation & 0.201 & 0.009 & 17637 & 21.37 & $<.001$ \\
\hline \multirow[t]{3}{*}{ Quadratic } & Intercept & 10.623 & 0.081 & 17636 & 131.49 & $<.001$ \\
\hline & Time orientation & -0.236 & 0.035 & 17636 & -6.84 & $<.001$ \\
\hline & Time orientation $^{2}$ & 0.042 & 0.003 & 17636 & 13.17 & $<.001$ \\
\hline \multirow[t]{4}{*}{ Cubic } & Intercept & 10.655 & 0.094 & 17635 & 113.46 & $<.001$ \\
\hline & Time orientation & -0.312 & 0.078 & 17635 & -3.99 & $<.001$ \\
\hline & Time orientation $^{2}$ & -0.061 & 0.018 & 17635 & 3.36 & $<.001$ \\
\hline & Time orientation $^{3}$ & -0.001 & 0.001 & 17635 & 0.28 & $=.281$ \\
\hline \multicolumn{7}{|c|}{ Association of Time orientation and Reproduction-maintenance trade-off } \\
\hline \multicolumn{7}{|c|}{ ESS Male } \\
\hline Models & Fixed effects & b & SE & df & $\mathbf{t}$ & $\mathrm{p}$ \\
\hline \multirow[t]{2}{*}{ Linear } & Intercept & 1.242 & 0.008 & 13424 & 155.59 & $<.001$ \\
\hline & Time orientation & 0.019 & 0.001 & 13424 & 13.76 & $<.001$ \\
\hline \multirow[t]{3}{*}{ Quadratic } & Intercept & 1.337 & 0.011 & 13423 & 119.04 & $<.001$ \\
\hline & Time orientation & -0.039 & 0.005 & 13423 & -7.75 & $<.001$ \\
\hline & Time orientation $^{2}$ & 0.006 & 0.001 & 13423 & 12.02 & $<.001$ \\
\hline \multirow[t]{4}{*}{ Cubic } & Intercept & 1.346 & 0.013 & 13422 & 102.32 & $<.001$ \\
\hline & Time orientation & -0.051 & 0.011 & 13422 & -4.62 & $<.001$ \\
\hline & Time orientation $^{2}$ & 0.009 & 0.003 & 13422 & 3.41 & $<.001$ \\
\hline & Time orientation $^{3}$ & $<-0.001$ & $<0.001$ & 13422 & -1.26 & $=.207$ \\
\hline \multicolumn{7}{|c|}{ ESS Female } \\
\hline Models & Fixed effects & b & SE & df & $\mathbf{t}$ & $\mathrm{p}$ \\
\hline \multirow[t]{2}{*}{ Linear } & Intercept & 1.569 & 0.01 & 17637 & 162.38 & $<.001$ \\
\hline & Time orientation & 0.033 & 0.002 & 17637 & 20.43 & $<.001$ \\
\hline \multirow[t]{3}{*}{ Quadratic } & Intercept & 1.734 & 0.014 & 17636 & 127.68 & $<.001$ \\
\hline & Time orientation & -0.064 & 0.006 & 17636 & -10.93 & $<.001$ \\
\hline & Time orientation ${ }^{2}$ & 0.009 & 0.001 & 17636 & 17.17 & $<.001$ \\
\hline \multirow[t]{4}{*}{ Cubic } & Intercept & 1.737 & 0.016 & 17635 & 109.83 & $<.001$ \\
\hline & Time orientation & -0.068 & 0.013 & 17635 & -5.17 & $<.001$ \\
\hline & Time orientation ${ }^{2}$ & 0.01 & 0.003 & 17635 & 3.36 & $<.001$ \\
\hline & Time orientation ${ }^{3}$ & $<-0.001$ & $<0.001$ & 17635 & -0.37 & $=.710$ \\
\hline
\end{tabular}

Supplementary Table S7. Fixed effects parameters of the exploratory EVS mixed models (Linear, Quadratic, Cubic). All models include random intercepts for each subject. 